Universidad de Lima

Facultad de Ciencias Empresariales y Económicas

Carrera de Contabilidad

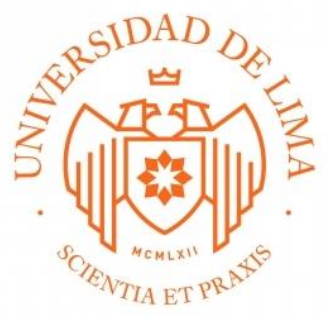

\title{
EL ANÁLISIS E INTERPRETACIÓN DE LOS ESTADOS FINANCIEROS Y SU IMPORTANCIA EN LA TOMA DE DECISIONES. CASO MICHELL \& CÍA S.A. 2015-2017
}

Trabajo de suficiencia profesional para optar el Título Profesional de Contador Público

\author{
Lili Wong Ho \\ Código 20112486
}

\author{
Asesor \\ Julio Segundo Catacora Díaz
}

Lima - Perú

Octubre de 2018 


\section{EL ANÁLISIS E INTERPRETACIÓN DE LOS} ESTADOS FINANCIEROS Y SU

\section{IMPORTANCIA EN LA TOMA DE}

DECISIONES. CASO MICHELL \& CÍA S.A.

$$
\text { 2015-2017 }
$$




\section{Dedicatoria}

Agradezco a:

A mis padres, ya que sin su esfuerzo no estaría hoy sustentando por el Título de Contador Público.

A mi asesor, por su paciencia y apoyo en este trabajo.

A los profesores de la Universidad de Lima, por compartirnos sus conocimientos y años de experiencia en esta carrera.

A mis compañeros de carrera que me apoyaron durante los ciclos más difíciles. 


\section{TABLA DE CONTENIDO}

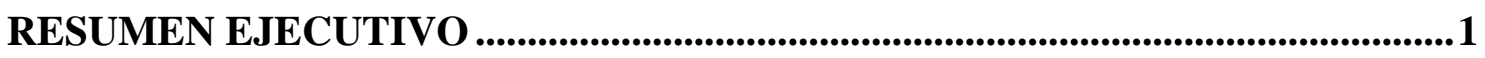

CAPÍTULO I: ANTECEDENTES DE LA ENTIDAD ..............................................2

1.1 Identificación y actividad económica de la entidad .................................................2

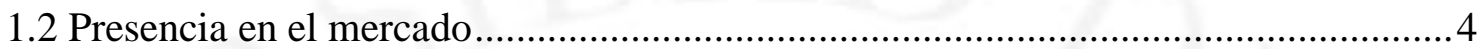

CAPÍTULO II: DESCRIPCIÓN Y OBJETIVOS DEL TRABAJO DE

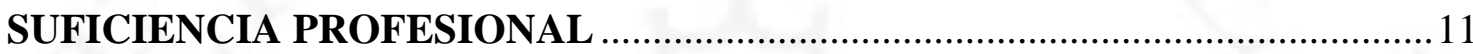

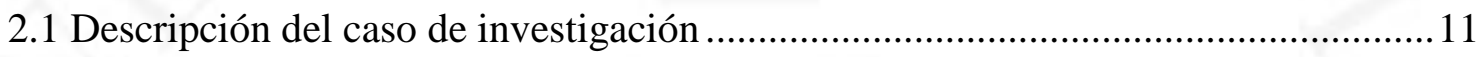

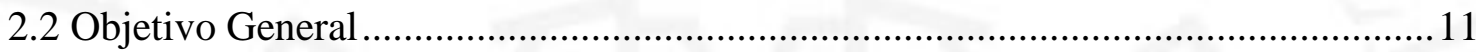

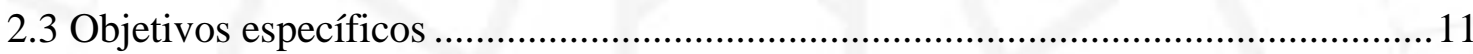

CAPÍTULO III: MARCO METODOLÓGICO .................................................... 12

3.1 Metodología de recolección de la información.................................................... 12

3.2 Metodología del análisis de la información ........................................................ 12

CAPÍTULO 4: ANÁLISIS Y PROYECCIÓN DE LA INFORMACIÓN

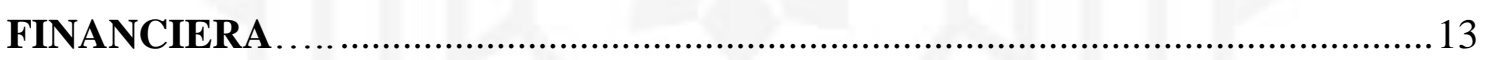

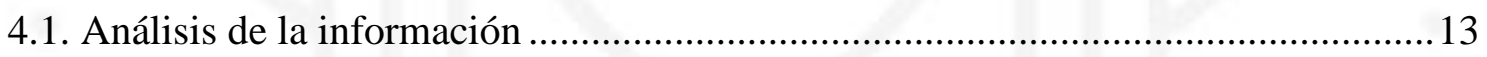

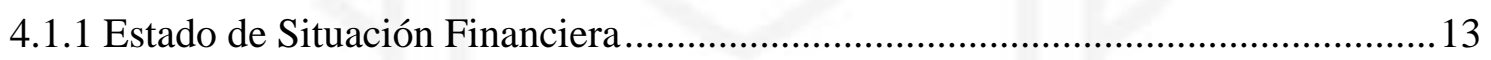

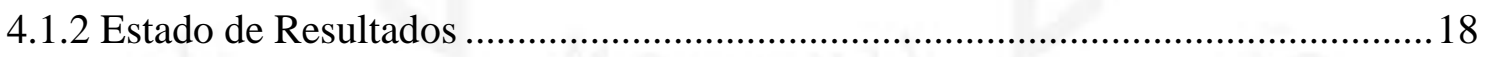

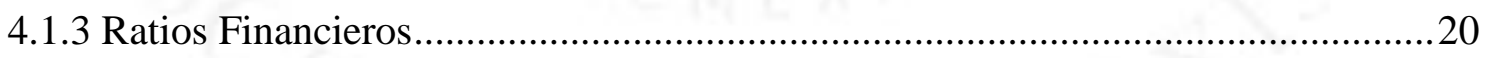

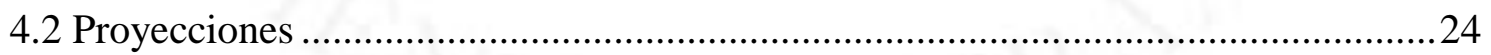

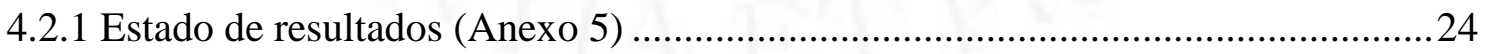

4.2.2 Estado de Situación Financiera (Anexo 6) ...........................................................29

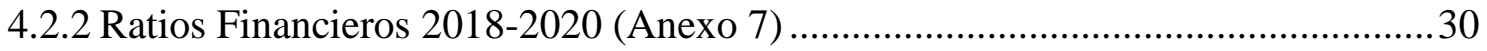

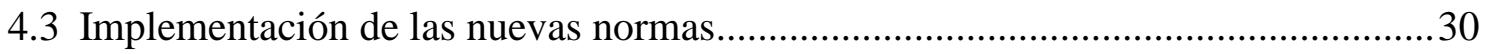

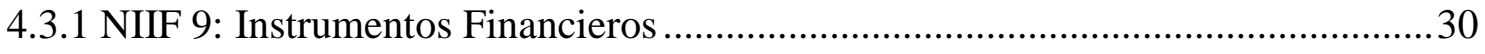




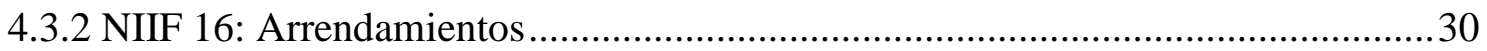

CAPÍTULO 5: CONCLUSIONES Y RECOMENDACIONES ..................................31

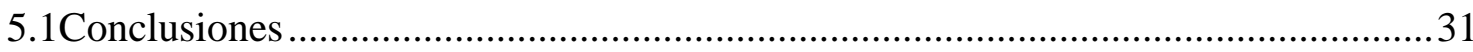

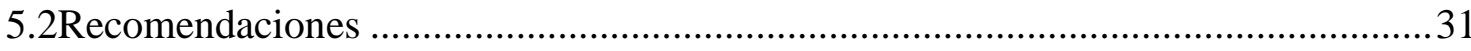

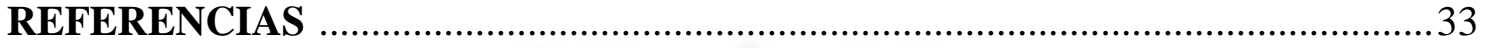

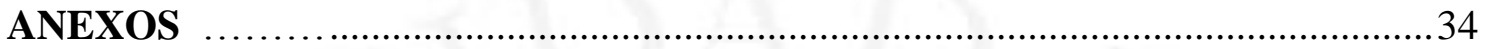




\section{ÍNDICE DE TABLAS}

Tabla 1. 1 Composición accionaria y participación en el patrimonio ..............................2

Tabla 1. 2 Acciones de Inversión............................................................................... 3

Tabla 1. 3 Variaciones del Producto Bruto Interno por tipo de gasto ............................ 5

Tabla 1. 4 Variaciones del PBI por Sectores Económicos ............................................. 7

Tabla 1. 5 Variaciones del crecimiento de la manufactura no primaria por tipo de bienes .8

Tabla 4. 1 Análisis Vertical - Estados de Situación Financiera 2015-2017 .................... 13

Tabla 4. 2 Composición de las obligaciones financieras 2015-2017 .............................. 14

Tabla 4. 3 Estructura de Participación Patrimonial 2017 ................................................ 15

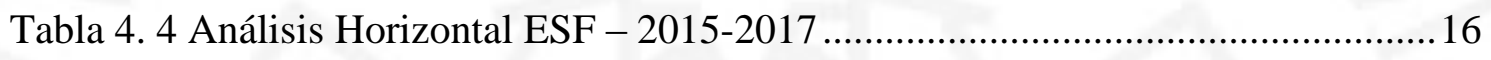

Tabla 4. 5 Detalle de la cuenta de Inventarios 2015-2017 ............................................. 17

Tabla 4. 6 Análisis Vertical Estado de Resultados - 2015-2017 .................................... 18

Tabla 4. 7 Composición de las ventas 2015-2017 …....................................................... 18

Tabla 4. 8 Análisis Horizontal del Estado de Resultados - 2015-2017 ......................... 19

Tabla 4. 9 Detalle de Ratios de Liquidez 2015-2017 ..................................................20

Tabla 4. 10 Detalle de Ratios de Solvencia 2015-2017 ...................................................21

Tabla 4. 11 Detalle de Ratios de Gestión 2015-2017 .....................................................22

Tabla 4. 12 Detalle de Ratios de Rentabilidad 2015-2017 .........................................23

Tabla 4. 13 Variación porcentual de la Demanda Interna y el PBI (Var. \% real anual). 25

Tabla 4. 14 Variación porcentual del PBI por sectores económicos (Var. \% real anual)

Tabla 4. 15 Supuestos para proyección de ventas 2018-2020 ….....................................27

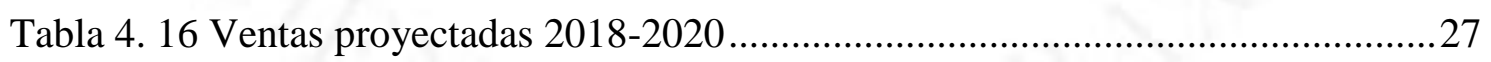

Tabla 4. 17 Detalle del Margen Bruto 2015-2017 .........................................................28

Tabla 4. 18 Detalle del Margen Bruto 2015-2017 …...................................................28 


\section{ÍNDICE DE FIGURAS}

Figura 1. 1 Variaciones del PBI y de la Demanda Interna ..........................................6

Figura 1. 2 Variaciones de la Manufactura no Primaria ................................................. 7

Figura 4. 1 Proyección de las exportaciones no tradicionales 2018-2021 (Var. Anual

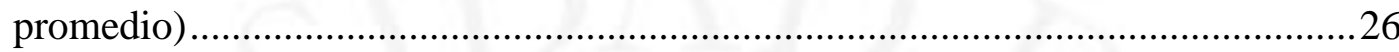




\section{ÍNDICE DE ANEXOS}

Anexo 1: Análisis Vertical del estado de Situación Financiera 2015-2017 ....................35

Anexo 2: Análisis Horizontal del estado de Situación Financiera 2015-2017 ................36

Anexo 3: Análisis Vertical del Estado de Resultados 2015-2017 ..................................38

Anexo 4: Análisis Horizontal del Estado de Resultados 2015-2017 ...............................39

Anexo 5: Proyección del Estado de Resultados 2018-2020 ….......................................40

Anexo 6: Proyección del Estado de Situación Financiera 2018-2020 ............................41

Anexo 7: Proyección del Ratios Financieros 2018-2020 ................................................43 


\section{RESUMEN EJECUTIVO}

Michell \& Cía. S.A. es una empresa con más de 83 años experiencia en el mercado de fabricación de tops e hilados de lana de oveja y fibra de alpaca.

La mayor parte de las ventas de la Compañía provienen de las exportaciones que realiza, considerándose en sus inicios como el primer exportador de tops e hilados de alpaca.

La Compañía es una empresa que se esfuerza por mantener la calidad de sus productos llegando a invertir grandes sumas en maquinaria y equipo para aumentar sus ventas y consolidar su liderazgo en cuanto a calidad dentro del sector textil industrial.

El objetivo del presente trabajo es realizar un análisis de la información financiera tomando como base los Estados Financieros Auditados por los períodos culminados del 2015-2017. Además, se proyectarán los estados financieros por los períodos 2018 al 2020 y evaluar la situación futura de la Compañía y si las decisiones tomadas en los períodos del 2015-2017 siguen siendo viables y rentables en el futuro. 


\section{CAPÍTULO I: ANTECEDENTES DE LA ENTIDAD}

\subsection{Identificación y actividad económica de la entidad}

Michell \& Cía. S.A. lleva más de 83 años de experiencia en el trabajo de procesamiento de fibra de alpaca, además fue el primer exportador y productor mundial de tops e hilados de alpaca (Michell \& Cía S.A., s. f.).

Fue constituida el 09 de febrero de 1982 y comenzó sus actividades el 24 de mayo de 1983.

Al 31 de diciembre del 2017 el capital social actual, suscrito y pagado es de 42 585454 y tiene aumentos de capital pendientes por el valor de S/.10 846122 provenientes del ajuste por corrección monetaria.

La composición accionaria y la participación en el patrimonio de la Compañía es la siguiente:

Tabla 1.1

Composición accionaria y participación en el patrimonio

\begin{tabular}{|l|c|c|}
\hline $\begin{array}{c}\text { \% de participación de } \\
\text { capital: }\end{array}$ & $\mathrm{N}^{\circ}$ de accionistas & \% Total de participación \\
\hline Hasta 1 & 1 & 0.41 \\
\hline De 1.01 al 5 & 7 & 15.24 \\
\hline De 5.01 al 10 & 3 & 18.39 \\
\hline De 10.01 al 20 & 3 & 36.78 \\
\hline De 20.01 al 30 & 1 & $\mathbf{1 0 0}$ \\
\hline Total & $\mathbf{1 5}$ & \\
\hline
\end{tabular}

Fuente: Michell y Cía S.A. (2018)

A continuación, se muestra el detalle de las acciones de inversión: 
Tabla 1.2

Acciones de Inversión

\begin{tabular}{|l|c|c|}
\hline Tenencia & $\mathbf{N}^{\circ}$ de Titulares & \% de Participación \\
\hline Menos al 1\% & 691 & 23.51 \\
\hline Entre el 1\% al 5\% & 7 & 12.96 \\
\hline Entre 5\% al 10\% & 1 & 8.22 \\
\hline Mayor al 10\% & 3 & 55.31 \\
\hline Total & $\mathbf{7 0 2}$ & $\mathbf{1 0 0 . 0 0}$ \\
\hline
\end{tabular}

Fuente: Michell y Cía S.A. (2018)

La empresa nació bajo el nombre de "Patten y Michell” el 7 de diciembre de 1931 teniendo como objetivo principal el acopio de fibra de alpaca y lana de oveja de la zona alto andina de la zona sur del Perú, para luego clasificarla y enviarla a distintos países de Europa. Posteriormente a 1946 la empresa empezó a abarcar no sólo la comercialización de la fibra de alpaca y lana de oveja como materia prima sino también la industrialización de la misma bajo del nombre de "Frank W. Mitchell".

En 1949, la empresa se convierte en la primera Empresa Peruana fabricante de hilados y tops gracias a la instalación de una planta de cardado, peinado e hilatura posicionándose como una de las primeras empresas exportadoras de alpaca.

Los tops se forman una vez que la lana ha pasado por el proceso de lavado y luego pasa por una máquina de tracción que le otorga un corte lanero para luego ser almacenada en grandes barriles. Estos tops mayormente son utilizados para hilados de tejidos de punto.

El top es un producto que es elaborado a pedido del cliente, los cuales suelen ser muy detallistas en cuanto a la calidad, finura y color ya que con estos elaborarán sus prendas y otros productos.

Durante el año 1949 la empresa cambia su nombre a Michell y Cía. S.R.L. A raíz del proceso de reconversión en Julio de 1957 cambia su nombre a Michell \& Cía. S.A.

Gracias a las leyes de fomento industrial, así como de la reinversión de las utilidades y los beneficios otorgados a las empresas descentralizadas Michell \& Cía. S.A. logra instalar en 1972 una planta de lavado, peinado y cardado en Arequipa. En ese 
mismo año moderniza las instalaciones dedicadas a los procesos de tintorería e hilandería de la planta ubicada en Tacna.

En la década de los ochenta debido al mayor apoyo a las exportaciones por parte de las legislaciones, al aumento de la demanda nacional, al perfeccionamiento del CERTEX, los créditos de FENT a la exportación y demás medidas que favorecieron el crecimiento industrial de la compañía se decidió que era momento de consolidarse, naciendo así las nuevas plantas que estaban destinadas a realizar procesos paralelos como Chachacoma S.A. (Lavado), Coropuna S.A., Texao S.A., Andes Lanas S.A., Alpalana S.A. y Alpateje S.A. (Hilatura).

En los años noventa debido a la crisis económica Michell \& Cía. S.A. se vio forzado a aplicar un proceso de reingeniería a todas las áreas de la compañía, producto de esto Alpalana S.A. absorbe mediante un proceso de fusión a las empresas Alpateje S.A., Chachacoma S.A. y Misti Lana S.A., y es así como en 1999 se forman dos empresas Alpalana S.A. y Michell \& Cía. S.A.

Bajo este escenario se realiza la producción en línea bajo dos razones sociales que abarcan tanto comercial y como fabrilmente, sin embargo, al momento de exportar dichos productos surgieron problemas relacionados con la imagen de la compañía ya que si bien es cierto los productos de ambas compañías eran los mismos, los de Michell \& Cía. S.A. eran más conocidos en el mercado internacional. Para solucionar dicho problema Alpalana S.A. cambia su razón social a Michell Industrial S.A. y esta se dedicó a la producción de tops e hilados mientras que Michell \& Cía. S.A se dedicó a la comercialización de una porción de los productos elaborados por la primera.

A finales de 1999 Michell Industrial absorbe a Michell \& Cía. S.A. y a comienzos del año 2000 se decide volver a la denominación de esta última.

\subsection{Presencia en el mercado}

El PBI en el año 2017 tuvo un alza de $2.5 \%$ a comparación el año 2016 que fue del 4\%, esta baja en el PBI se debe básicamente a la polémica que generó el caso de corrupción Lava Jato y al fenómeno del Niño Costero.

El primero afectó de manera negativa la confianza de los inversionistas y estancó los proyectos de inversión de las Asociaciones Público-Privadas, mientras que el segundo 
deterioró de manera significativa la infraestructura de la zona norte del país. Estos dos fenómenos atenuaron el crecimiento de la demanda interna de ese año.

Como consecuencia de éstos se vio afectada de manera importante la inversión privada al verse detenidos grandes proyectos como el del Gaseoducto Sur Peruano, el proyecto de irrigación Chavimochic, entre otros. Sin embargo, a comparación de años anteriores logró detener la contracción que venía sufriendo desde hace tres años.

A diferencia del consumo privado que si bien hubo un leve recupero a inicios de año no logró recuperar la tendencia de crecimiento que tuvo en años anteriores (Banco Central de Reserva del Perú, 2017).

Tabla 1.3

Variaciones del Producto Bruto Interno por tipo de gasto

\begin{tabular}{|c|c|c|c|c|}
\hline \multicolumn{5}{|c|}{$\begin{array}{c}\text { Cuadro } 1 \\
\text { PRODUCTO BRUTO INTERNO POR TIPO DE GASTO } \\
\text { (Variaciones porcentuales reales) }\end{array}$} \\
\hline & 2015 & 2016 & 2017 & $\begin{array}{l}\text { Promedio } \\
\text { 2008-2017 }\end{array}$ \\
\hline Demanda Interna & 2,9 & 1,1 & 1,6 & 5,4 \\
\hline a. Consumo privado & 4,0 & 3,3 & 2,5 & 5,5 \\
\hline b. Consumo público & 9,8 & $-0,6$ & 1,0 & 5,9 \\
\hline c. Inversión bruta fija & $-5,2$ & $-4,7$ & $-0,3$ & 5,9 \\
\hline - Privada & $-4,2$ & $-5,7$ & 0,3 & 5,6 \\
\hline - Pública & $-9,5$ & $-0,2$ & $-2,3$ & 7,2 \\
\hline \multirow{2}{*}{$\begin{array}{l}\text { Variación de existencias } \\
\text { (\% del PBI nominal) }\end{array}$} & & & & \\
\hline & $-0,4$ & $-0,2$ & $-0,2$ & $-0,3$ \\
\hline Exportaciones & 4,0 & 9,5 & 7,2 & 3,8 \\
\hline \multicolumn{5}{|l|}{ Menos: } \\
\hline Importaciones & 2,4 & $-2,2$ & 4,0 & 5,6 \\
\hline Producto Bruto Interno & 3,3 & 4,0 & 2,5 & 4,9 \\
\hline \multicolumn{5}{|l|}{ Nota: } \\
\hline Gasto público total & 3,6 & $-0,5$ & 0,1 & 6,2 \\
\hline
\end{tabular}

Fuente: Banco Central de Reserva del Perú (2017) 
Figura 1. 1

Variaciones del PBI y de la Demanda Interna

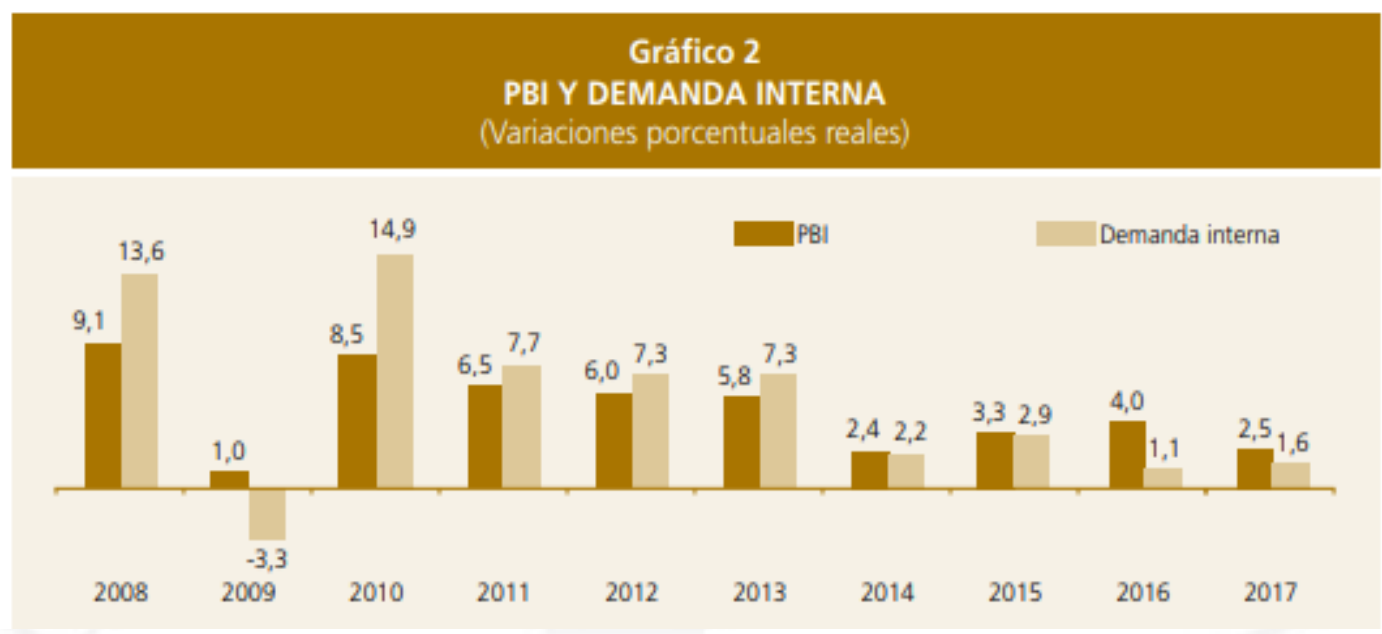

Fuente: Banco Central de Reserva del Perú (2017)

Las actividades de Michell \& Cía. S.A. se encuentran dentro del sector de manufactura no primaria.

El sector de manufactura tuvo una caída del $3 \%$, en específico en la actividad manufacturera no primaria, esto es debido a una disminución de las exportaciones y de la producción de bienes de capital e insumos para el mercado interno.

La manufactura no primaria tuvo su cuarto año de caída consecutiva registrando una disminución del $9 \%$ en el 2017, gran parte de esta caída se debe a los efectos generados por el Fenómeno El Niño que provocaron problemas con el abastecimiento de insumos, déficit de mano de obra por el cierre de carreteras, caminos y puentes, daños en las infraestructuras de las fábricas y maquinarias, así como también problemas con el transporte. 
Figura 1. 2

Variaciones de la Manufactura no Primaria

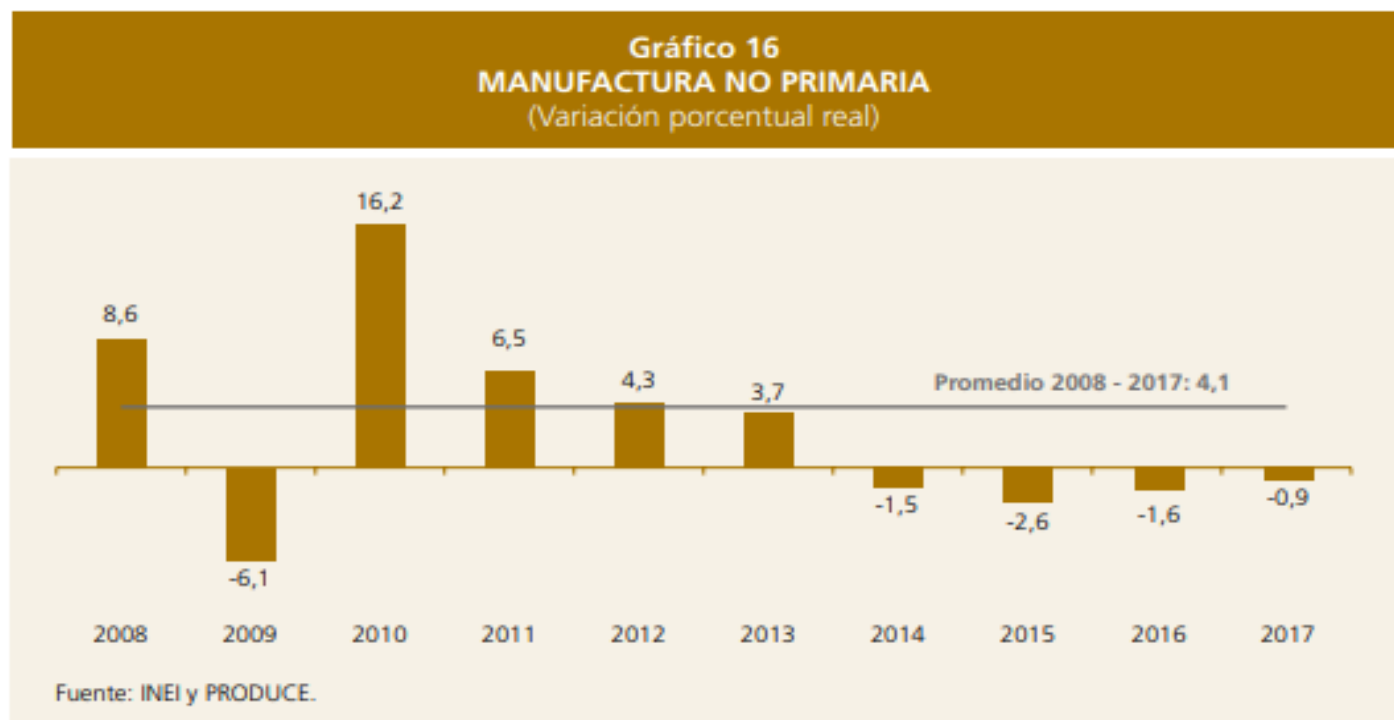

Fuente: Banco Central de Reserva del Perú (2017)

Tabla 1.4

Variaciones del PBI por Sectores Económicos

\begin{tabular}{|c|c|c|c|c|}
\hline \multicolumn{5}{|c|}{$\begin{array}{c}\text { Cuadro } 5 \\
\text { PRODUCTO BRUTO INTERNO POR SECTORES ECONÓMICOS 1/ } \\
\text { (Variaciones porcentuales reales) }\end{array}$} \\
\hline & 2015 & 2016 & 2017 & $\begin{array}{l}\text { Promedio } \\
2008-2017\end{array}$ \\
\hline Agropecuario $2 /$ & 3,5 & 2,7 & 2,6 & 3,6 \\
\hline Agricola & 2,3 & 1,8 & 2,6 & 3,3 \\
\hline Pecuario & 5,2 & 3,7 & 2,7 & 4,7 \\
\hline Pesca & 15,9 & $-10,1$ & 4,7 & $-2,1$ \\
\hline Minería e hidrocarburos 3 / & 9,5 & 16,3 & 3,2 & 4,6 \\
\hline Mineria metálica & 15,7 & 21,2 & 4,2 & 4,3 \\
\hline Hidrocarburos & $-11,5$ & $-5,1$ & $-2,4$ & 3,3 \\
\hline Manufactura 4/ & $-1,5$ & $-1,4$ & $-0,3$ & 1,9 \\
\hline Recursos primarios & 1,8 & $-0,6$ & 1,9 & 0,3 \\
\hline Manufactura no primaria & $-2,6$ & $-1,6$ & $-0,9$ & 2,5 \\
\hline Electricidad y agua & 5,9 & 7,3 & 1,1 & 5,5 \\
\hline Construcción & $-5,8$ & $-3,1$ & 2,2 & 6,2 \\
\hline Comercio & 3,9 & 1,8 & 1,0 & 5,5 \\
\hline Servicios & 4,2 & 4,0 & 3,4 & 5,8 \\
\hline PRODUCTO BRUTO INTERNO & 3,3 & 4,0 & 2,5 & 4,9 \\
\hline \multicolumn{5}{|l|}{ Nota: } \\
\hline PBI primario & 6,9 & 10,0 & 2,9 & 3,6 \\
\hline PBI no primario & 2,4 & 2,4 & 2,4 & 5,3 \\
\hline
\end{tabular}

Fuente: Banco Central de Reserva del Perú (2017) 
Todas las áreas vinculadas a exportaciones tuvieron una disminución del 1.9\% como resultado de la menor producción de hilados, tejidos, acabados y prendas de vestir durante el primer semestre del año.

La industria textil se fue recuperando durante la segunda mitad del año gracias a la demanda externa de productos nuevos en los mercados nichos y a la entrada de nuevos clientes

Tabla 1.5

Variaciones del crecimiento de la manufactura no primaria por tipo de bienes

\begin{tabular}{|c|c|c|c|c|}
\hline \multicolumn{5}{|c|}{$\begin{array}{c}\text { Cuadro } 12 \\
\text { CRECIMIENTO DE LA MANUFACTURA NO PRIMARIA POR TIPO DE BIENES } \\
\text { (Nariaciones porcentuales reales) }\end{array}$} \\
\hline & 2015 & 2016 & 2017 & $\begin{array}{l}\text { Promedio } \\
2008-2017\end{array}$ \\
\hline Consumo masivo & 0,2 & 1,5 & 0,2 & 3,1 \\
\hline Productos lacteos & 3,1 & $-4,6$ & $-4,9$ & 2,9 \\
\hline Panaderia & 1,2 & $-4,6$ & 3,1 & 0,8 \\
\hline Aceites y grasas & 4,5 & 2,3 & 6,5 & 4,1 \\
\hline Productos alimenticios diversos & $-8,0$ & $-6,2$ & 14,7 & 4,2 \\
\hline Cerveza y malta & $-0,4$ & $-0,8$ & 0,0 & 2,6 \\
\hline Bebidas gaseosas & 9,1 & 7,2 & $-3,9$ & 6,2 \\
\hline Prendas de vestir & $-8,7$ & $-4,2$ & $-4,3$ & $-2,2$ \\
\hline Calzado & 3,0 & 4,1 & 16,2 & 7,3 \\
\hline Muebles & 7,8 & 5,7 & $-5,1$ & 7,3 \\
\hline Otros articulos de papel y cartón & 12,5 & 1,6 & 12,7 & 7,9 \\
\hline Productos de tocador y limpieza & $-1,9$ & 9,8 & $-14,9$ & 2,6 \\
\hline Productos farmacéuticos & $-20,4$ & 10,1 & $-8,0$ & $-2,5$ \\
\hline Manufacturas diversas & $-6,0$ & $-9,9$ & 15,0 & $-0,9$ \\
\hline Exportaciones & $-6,3$ & $-4,2$ & $-1,9$ & $-1,5$ \\
\hline Conservas de almentos & $-4,2$ & 4,1 & $-2,9$ & 3,3 \\
\hline Fibras sinteticas & $-10,5$ & $-4,0$ & 0,9 & $-3,1$ \\
\hline Hilados, tejidos y acabados & $-5,1$ & $-7,7$ & $-1,6$ & $-2,6$ \\
\hline Tejidos y artículos de punto & $-5,9$ & $-10,2$ & 4,1 & $-3,4$ \\
\hline Prendas de vestir & $-8,7$ & $-4,2$ & $-4,3$ & $-2,2$ \\
\hline Insumos & $-4,4$ & $-0,7$ & $-3,2$ & 1,6 \\
\hline Harina de trigo & 0,6 & $-4,4$ & 0,6 & 1,3 \\
\hline Otros productos textiles & $-7,0$ & $-1,0$ & 8,9 & $-1,7$ \\
\hline Madera & $-11,0$ & $-4,4$ & $-32,0$ & $-8,7$ \\
\hline Papel y cartón & $-16,6$ & $-5,5$ & $-7,3$ & 0,0 \\
\hline Erwases de papel y carton & 1,4 & 7,4 & 7,9 & 4,9 \\
\hline Actividades de edición e impresion & $-17,9$ & 2,5 & $-16,6$ & 0,3 \\
\hline Sustancias quimicas basicas & 0,9 & $-6,4$ & 5,3 & 1,4 \\
\hline Explosivos, esencias naturales y químicas & 19,6 & 3,9 & $-3,7$ & 7,9 \\
\hline Caucho & $-5,2$ & $-10,5$ & 6,6 & $-2,0$ \\
\hline Plasticos & $-1,7$ & $-0,8$ & 1,3 & 4,7 \\
\hline Vidrio & 0,2 & 9,5 & 2,3 & 10,1 \\
\hline Orientados a la inversión & $-3,6$ & $-5,1$ & $-0,4$ & 4,8 \\
\hline Industria del hierro y acero & $-3,6$ & 2,2 & 4,5 & 0,7 \\
\hline Productos metálicos & 2,8 & $-10,2$ & $-3,8$ & 6,6 \\
\hline Maquinaria y equipo & $-7,3$ & $-9,2$ & 22,8 & 2,2 \\
\hline Maquinaria electrica & $-30,5$ & 15,6 & $-5,2$ & $-1,0$ \\
\hline Material de transporte & $-7,1$ & $-16,2$ & $-5,6$ & 5,7 \\
\hline Pinturas, barnices y lacas & $-2,4$ & $-9,1$ & 5,3 & 4,8 \\
\hline Cemento & $-1,9$ & 1,5 & 0,7 & 5,5 \\
\hline Materiales para la construcción & $-3,1$ & $-5,4$ & $-3,0$ & 4,1 \\
\hline Servicios industriales & $-7,0$ & $-2,6$ & $-4,5$ & 7,9 \\
\hline Total Manufactura no Primaria & $-2,6$ & $-1,6$ & $-0,9$ & 2,5 \\
\hline
\end{tabular}

Fuente: Banco Central de Reserva del Perú (2017) 
Michell \& Cía. S.A. en la actualidad es asociada con los más finos hilados de Alpaca Peruana siendo reconocida por su calidad en los mercados de Europa, América y Asia.

La actividad principal de Michell \& Cía. S.A. es la fabricación, comercio interno y externo de tops e hilados de fibra de alpaca, lana de oveja y/o fibras acrílicas, así como también de las actividades anexas y complementarias a éstas.

Su proceso de industrialización de la fibra es el siguiente:

1. Esquila: Proceso por el cual se corta y separa el conjunto total de fibra que cubre a la alpaca llamada también vellón. Entre los vellones que se esquilan se encuentran el manto que es la fibra que se halla en el lomo y los flancos, mientras que la que se encuentra en el pectoral, extremidades y cabeza se denomina bragas.

2. Escojo: Es el proceso donde una vez recibida la fibra esta pasa a ser clasificada manualmente por origen, calidad, color y largo.

3. Una vez terminado este proceso la fibra pasa por diferentes procesos industriales como el lavado, cardado, peinado y teñido.

4. Hilatura: Proceso en el que la fibra es enrollada alrededor de cilindros formando ovillos que luego son embalados en pallets para su despacho (Adot, 2010)

Michell \& Cía. S.A. se desarrolla en el Sector Textil, específicamente en la fabricación de Tops e Hilados de lana de oveja, pelo de alpaca y mezclas llegando a tener un $7 \%$ de participación en este mercado (Michell \& Cía. S.A., 2018).

En el sector textil, en específico la del sector de fibra de alpaca, el mercado arequipeño ocupa un lugar importante dentro de la misma llegando a tener el liderazgo.

Como distintivas de este mercado se encuentran las dos empresas privadas Michell \& Cía. S.A. e Incatops S.A. que cuentan con el 37 \% de participación de mercado, mientras que el otro $63 \%$ está representado por 350 empresas cuyas ventas individuales 
no superan el millón de dólares de ventas anuales (Rodriguez, Valdivia, \& Velazco, 2018).

Ambos tienen como ventaja competitiva que tienen sus cadenas de valor integradas verticalmente y que juntas representan el $90 \%$ de las exportaciones de fibras de alpaca. 


\section{CAPÍTULO II: DESCRIPCIÓN Y OBJETIVOS DEL TRABAJO DE SUFICIENCIA PROFESIONAL}

\subsection{Descripción del caso de investigación}

El presente trabajo tiene como objetivo principal realizar un análisis financiero teniendo como base los Estados Financieros auditados de Michell \& Cía. S.A. por los períodos culminados del 2015-2017 y su relevancia e impacto en la toma de decisiones.

\subsection{Objetivo General}

Analizar los estados financieros de Michell \& Cía. S.A. por los períodos del 2015 - 2017 en relación a las decisiones tomadas y su relación directa con el desempeño de la Compañía durante esos períodos y la viabilidad de las mismas sobre el desempeño futuro.

\subsection{Objetivos específicos}

Objetivo Específico 1: Evaluar el desempeño de la compañía durante esos períodos y su desarrollo en el tiempo, para tal motivo se pretende realizar un análisis de los principales indicadores financieros tales como las ratios de liquidez, endeudamiento, de gestión, etc.

Objetivo Específico 2: Evaluar el impacto de las decisiones tomados en los períodos en estudio en relación con los estados financieros.

Objetivo Específico 3: Además, se hará un análisis financiero sobre el desempeño futuro de la compañía, para tal motivo se realizará una proyección de los estados financieros de Michell \& Cía. S.A. por los períodos del 2018 al 2020. 


\section{CAPÍTULO III: MARCO METODOLÓGICO}

\subsection{Metodología de recolección de la información}

Para la elaboración del presente análisis se utilizará información de diferentes fuentes tales como: información proveniente de páginas web (BCRP, MEF, PRODUCE, entre otros), informes del crecimiento del sector en donde se pueden identificar las principales tendencias de crecimiento de la compañía, tesis o trabajos de investigación referentes al sector textil-industrial, memorias anuales, etc.

\subsection{Metodología del análisis de la información}

El presente trabajo se llevará a cabo mediante la contrastación de información de fuentes secundarias y la relación con el desempeño durante los períodos 2015-2017. También se llevará acabo el análisis e interpretación de los indicadores financieros, así como un análisis vertical y horizontal de los estados financieros de la Compañía.

Además, se realizarán las proyecciones de los Estados Financieros desde el 2018 al 2020 y se evaluará el desempeño futuro de la Compañía en base a la información recolectada por los períodos cerrados del 2015 al 2017. 


\section{CAPÍTULO 4: ANÁLISIS Y PROYECCIÓN DE LA INFORMACIÓN FINANCIERA}

\subsection{Análisis de la información}

En las siguientes líneas se realizará un análisis financiero del Estado de Situación Financiera, del Estado de Resultados y de los Ratios de la Compañía por los períodos $2015-2017$.

\subsubsection{Estado de Situación Financiera}

A continuación, se presenta el Análisis Vertical y Horizontal del Estado de Situación Financiera Separado de la Compañía Michell \& Cía. S.A. por los períodos 2015-2017, del cual se analizará las principales variaciones y composiciones de los rubros más significativos.

\subsubsection{Análisis vertical (Anexo1)}

Tabla 4. 1

Análisis Vertical - Estados de Situación Financiera 2015-2017

\begin{tabular}{|c|c|c|c|c|c|c|}
\hline & \multicolumn{2}{|c|}{2017} & \multicolumn{2}{|l|}{2016} & \multicolumn{2}{|c|}{2015} \\
\hline Activo Corriente & Var. SI. (000) & $\%$ & Var. Sl. $(000)$ & $\%$ & Var. SI. (000) & $\%$ \\
\hline Cuentas por cobrar comerciales & 62,906 & $14.70 \%$ & 41,130 & $11.95 \%$ & 46,505 & $14.30 \%$ \\
\hline Inventarios & 184,393 & $43.08 \%$ & 148,639 & $43.18 \%$ & 123,721 & $38.05 \%$ \\
\hline Activos no corriente & SI. (000) & $\%$ & SI. (000) & $\%$ & SI. (000) & $\%$ \\
\hline Propiedad, planta y equipo & 127,686 & $29.83 \%$ & 109,634 & $31.85 \%$ & 108,280 & $33.30 \%$ \\
\hline Pasivo Corriente & SI. (000) & $\%$ & SI. $(000)$ & $\%$ & SI. $(000)$ & $\%$ \\
\hline Obligaciones financieras & 133,577 & $31.21 \%$ & 70,819 & $20.57 \%$ & 66,376 & $20.41 \%$ \\
\hline Patrimonio & SI. $(000)$ & $\%$ & SI. $(000)$ & $\%$ & SI. (000) & $\%$ \\
\hline Capital emitido & 53,432 & $12.48 \%$ & 53,432 & $15.52 \%$ & 53,432 & $16.43 \%$ \\
\hline Excedente de revaluación & 56,622 & $13.23 \%$ & 56,622 & $16.45 \%$ & 56,622 & $17.41 \%$ \\
\hline Resultados acumulados & 128,008 & $29.91 \%$ & 114,485 & $33.26 \%$ & 100,123 & $30.79 \%$ \\
\hline
\end{tabular}

Fuente: Superintendencia del Mercado de Valores. (s. f.a, s.f.b, s.f.c). Elaboración propia

En el Activo Corriente por los períodos 2015 -2017 se puede observar que las cuentas por cobrar comerciales de Michell \& Cía. S.A. derivan en su totalidad de las 
ventas nacionales e internaciones de hilados y tops de lana y alpaca tomados con vencimiento corriente que no cuentan con garantías ni devengan intereses.

Gran porcentaje en la cuenta de Inventarios se debe a que la Compañía se desempeña principalmente en el sector industrial, sus inventarios están compuestas principalmente por mercaderías (tops e hilados de lana y alpaca), productos terminados, productos en proceso y materias primas. Además, también se encuentran materiales auxiliares, suministros, repuestos, inventarios por recibir y los anticipos a proveedores.

En los Activos no corrientes por los períodos 2015-2017 se observa que la Propiedad, Planta y Equipo contiene en su mayoría las maquinarias y equipos, terrenos, edificios y otras construcciones de la compañía.

Cabe mencionar que dentro de este rubro también se encuentran los activos bilógicos de la misma que están conformados en específico por camélidos sudamericanos (en especial alpacas y llamas), los cuales son utilizados como muestra en "en vivo" del proceso de transformación artesanal e industrial de las llamas y alpacas.

Las obligaciones financieras se conforman principalmente en préstamos bancarios, sobregiros bancarios y pagarés que son necesarios para las operaciones de la Compañía. A continuación, se muestra el detalle del rubro:

Tabla 4. 2

Composición de las obligaciones financieras 2015-2017

\begin{tabular}{|l|r|r|r|}
\hline & \multicolumn{1}{|c|}{$\mathbf{2 0 1 7}(\mathbf{S} /)}$. & $\mathbf{2 0 1 6}(\mathbf{S} /)$. & $\mathbf{2 0 1 5}$ (SI.) \\
\hline Sobregiros Bancarios & 112,794 & 106,521 & 90,663 \\
\hline Préstamos bancarios & $130,204,297$ & $60,652,099$ & $54,952,484$ \\
\hline Pagarés & $3,259,814$ & $10,060,000$ & $11,332,686$ \\
\hline Total & $\mathbf{1 3 3 , 5 7 6 , 9 0 5}$ & $\mathbf{7 0 , 8 1 8 , 6 2 0}$ & $\mathbf{6 6 , 2 8 5 , 1 7 0}$ \\
\hline
\end{tabular}

Fuente: Superintendencia del Mercado de Valores. (s. f.a, s.f.b, s.f.c).

Elaboración propia

Al cierre del 31 de diciembre del 2017, el capital social de la Compañía se encuentra con un total de 42585454 acciones comunes con un valor nominal de S/ 1.00 por acción.

El capital social histórico llega a la suma de S/ 53431576 dejando un saldo por capitalizar de S/ 10846 122, dicho saldo proviene de los ajustes por corrección del tipo de cambio. 
Además, al 31 de diciembre del 2017 quedan pendiente la suscripción y emisión del capital social que asciende a S/ 10846 122, provenientes del capital acumulado al cierre del 31 de diciembre del 2004, dicha suma corresponde a los ejercicios culminados comprendidos entre 1997 a 2004.

Según los Estados Financieros auditados al cierre al 31 de diciembre del 2017, la participación del capital social se encuentra representada de la siguiente manera:

Tabla 4. 3

Estructura de Participación Patrimonial 2017

\begin{tabular}{|c|c|c|c|c|c|}
\hline \multicolumn{6}{|c|}{ Estructura de Participación Accionariada } \\
\hline \multicolumn{4}{|c|}{$\begin{array}{l}\text { \% de participación individual } \\
\text { de capital }\end{array}$} & \multirow{2}{*}{$\begin{array}{c}\mathrm{N}^{\circ} \\
\text { accionistas } \\
1\end{array}$} & \multirow{2}{*}{$\begin{array}{l}\begin{array}{c}\% \text { total de } \\
\text { Participación }\end{array} \\
0.41\end{array}$} \\
\hline $\mathrm{De}$ & 0 & hasta & 1 & & \\
\hline $\mathrm{De}$ & 1.01 & al & 5 & 7 & 15.24 \\
\hline $\mathrm{De}$ & 5.01 & al & 10 & 3 & 18.39 \\
\hline $\mathrm{De}$ & 10.01 & al & 20 & 3 & 36.78 \\
\hline $\mathrm{De}$ & 20.01 & al & 30 & 1 & 29.18 \\
\hline \multicolumn{4}{|c|}{ TOTAL } & 15 & 100.00 \\
\hline
\end{tabular}

Fuente: Michell \& Cía. (2018)

El excedente de revaluación se debe principalmente a las siguientes revaluaciones:

1. La revaluación voluntaria de 8 máquinas de cardas de marca Octir y Thibeau por un monto de S/ 6791 295.44, dicha revaluación fue acordada en la Junta General de Accionistas celebrada el 20 de diciembre del 2004.

2. La revaluación del inmueble ubicado en el Parque Industrial Pocollay Tacna que ascendió a S/ 5191 096.77, dicha revaluación fue acordada en la Junta General de Accionistas celebrada el 9 de diciembre del 2011.

3. El 31 de diciembre del 2011 y 2013 se lleva a cabo la valorización de activos fijos de acuerdo a las Normas Internacionales de Información Financiera (NIIF) que resultó en un incremento de S/. 28422181.65 y S/. 16217762.55 , respectivamente. 
En la cuenta de resultados acumulados se encuentran los resultados de los ejercicios que derivan de las operaciones económicas de la Compañía.

\subsubsection{Análisis Horizontal}

A continuación, se realizará un análisis horizontal del Estado de Situación Financiera (Anexo 2) por los períodos culminados del 2015 al 2017, en donde se encontraron las siguientes observaciones:

Tabla 4. 4

Análisis Horizontal ESF - 2015-2017

\begin{tabular}{|l|r|r|r|r|}
\hline & \multicolumn{2}{|c|}{$\begin{array}{c}\text { Análisis Horizontal } \\
\text { (Dic 17 - Dic 16) }\end{array}$} & \multicolumn{2}{c|}{$\begin{array}{c}\text { Análisis Horizontal } \\
\text { (Dic 16 - Dic 15) }\end{array}$} \\
\hline Activo Corriente & Var. SI. (000) & $\%$ & Var. SI. (000) & $\%$ \\
\hline Cuentas por cobrar comerciales & 21,776 & $52.96 \%$ & 5,376 & $11.56 \%$ \\
\hline Inventarios & 35,753 & $24.06 \%$ & 24,918 & $20.14 \%$ \\
\hline & & & & \\
\hline Activos no corriente & SI. (000) & $\%$ & SI. (000) & $\%$ \\
\hline Propiedad, planta y equipo & 18,061 & $16.40 \%$ & 1,364 & $1.25 \%$ \\
\hline & & & & \\
\hline Pasivo Corriente & SI. (000) & $\%$ & SI. (000) & $\%$ \\
\hline Obligaciones financieras & 62,758 & $88.62 \%$ & 4,443 & $6.69 \%$ \\
\hline & & & & \\
\hline Patrimonio & SI. (000) & $\%$ & SI. (000) & $\%$ \\
\hline Resultados acumulados & 13,524 & $11.81 \%$ & 14,361 & $14.34 \%$ \\
\hline
\end{tabular}

Fuente: Superintendencia del Mercado de Valores. (s. f.a, s.f.b, s.f.c). Elaboración propia

El aumento de las cuentas por cobrar comerciales está ligado directamente al incremento de las ventas, que al cierre al 31 de diciembre del 2017 tuvieron un incremento del $17 \%$ a comparación del 2016.

Además, el despunte del aumento en el 2017 se debe a las consecuencias derivadas de los sucesos del Fenómeno del Niño y del Caso Lava Jato que originaron dificultades de pago por parte de los clientes lo que hizo que las cuentas por cobrar comerciales aumentaran.

La cuenta de Inventarios se encuentra constituida de la siguiente manera: 


\section{Tabla 4. 5}

Detalle de la cuenta de Inventarios 2015-2017

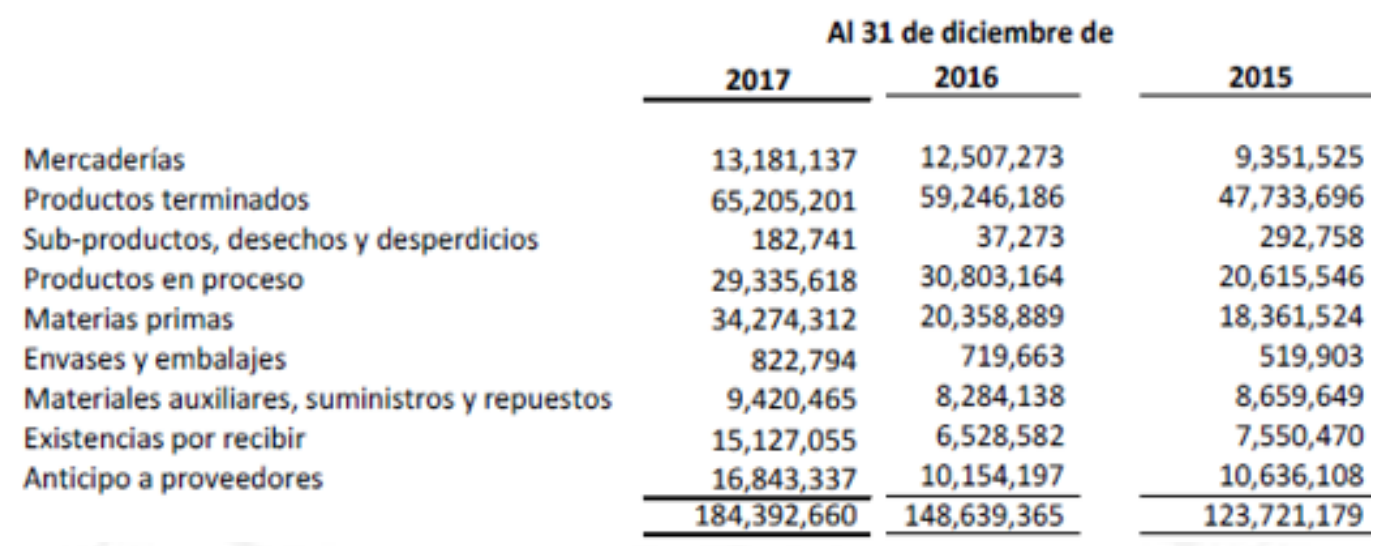

Fuente: Superintendencia del Mercado de Valores. (s. f.a, s.f.b, s.f.c).

Como se puede observar en las notas de los estados financieros auditados el mayor incremento de la cuenta se debe a la mayor adquisición de materia prima requerida para satisfacer el aumento de la demanda en el período 2017.

Además, la adquisición de materia prima se da bajo la modalidad de anticipos a proveedores lo que garantiza el flujo continuo en el abastecimiento de lana de oveja y pelo de alpaca.

En la cuenta de Propiedad, planta y equipo se puede observar que el aumento en esta cuenta se debe a que en el 2017 y 2016 se realizaron grandes proyectos de inversión en activos fijos que tuvieron como objetivo incrementar las ventas y consolidar el liderazgo de la Compañía en el mercado. En esos mismos períodos también se adquirieron activos fijos bajo arrendamiento financiero por un valor de S/ 826699.

Al término de del 2017 la Compañía adquirió activos fijos por un valor de S/ 26 474 miles de soles mientras que en el 2016 se realizaron compras de activos fijos por un valor de S/10 391 miles de soles. Además, en el 2017 Michell y Cía. S.A. adquirió un local de $4103 \mathrm{~m} 2$ que colinda con sus plantas de acabados por un valor de S/ 7359750.

Las obligaciones financieras en el 2017 tuvieron un incremento debido al mayor aumento de préstamos bancarios que fueron utilizados para solventar las brechas de liquidez que surgiesen en el período, para estas últimas se solicitaron préstamos sobre futuras ventas al exterior a corto plazo. 
Como se mencionó anteriormente el aumento de la partida de resultados acumulados se debe al incremento de los beneficios obtenidos por las actividades económicas ordinarias de la Compañía.

\subsubsection{Estado de Resultados}

\subsubsection{Análisis Vertical}

A continuación, se realizará un análisis vertical del Estado de Resultados (Anexo 3) por los períodos culminados del 2015 al 2017, en dónde se encontraron las siguientes observaciones:

Tabla 4. 6

Análisis Vertical Estado de Resultados - 2015-2017

\begin{tabular}{|c|c|c|c|c|c|c|}
\hline & \multicolumn{2}{|c|}{2017} & \multicolumn{2}{|c|}{2016} & \multicolumn{2}{|c|}{2015} \\
\hline & SI. (000) & $\%$ & SI. (000) & $\%$ & S/. (000) & $\%$ \\
\hline Ventas & 377,913 & $100.00 \%$ & 324,045 & $100.00 \%$ & 328,188 & $100.00 \%$ \\
\hline Costos de Ventas & 295,968 & $78.32 \%$ & 237,773 & $73.38 \%$ & 246,845 & $75.21 \%$ \\
\hline Ingresos (gastos) operativos & SI. (000) & $\%$ & SI. (000) & $\%$ & SI. (000) & $\%$ \\
\hline Gastos Administrativos & 17,820 & $4.72 \%$ & 22,306 & $6.88 \%$ & 18,380 & $5.60 \%$ \\
\hline
\end{tabular}

Fuente: Superintendencia del Mercado de Valores. (s. f.a, s.f.b, s.f.c).

Elaboración propia

Michell \& Cía. S.A. tienes sus ventas divididas en ventas dentro del país y ventas al exterior. La distribución de las ventas para los 2015 al 2017 es la siguiente:

Tabla 4.7

Composición de las ventas 2015-2017

\begin{tabular}{|l|r|r|r|}
\hline & Al 31.12.2017 & Al 31.12.2016 & Al 31.12.2015 \\
\hline Ventas dentro del pais & $148,166,351$ & $83,117,732$ & $107,405,293$ \\
\hline Ventas al exterior & $299,746,158$ & $240,927,627$ & $220,783,000$ \\
\hline Total & $\mathbf{3 7 7 , 9 1 2 , 5 0 9}$ & $\mathbf{3 2 4 , 0 4 5 , 3 5 9}$ & $\mathbf{3 2 8 , 1 8 8 , 2 9 3}$ \\
\hline
\end{tabular}

Fuente: Superintendencia del Mercado de Valores. (s. f.a, s.f.b, s.f.c).

Elaboración propia

El costo de ventas de la compañía se encuentra en su mayor parte constituido por el costo de materia prima y por la carga de personal llegando a representar el $90 \%$ del mismo. 
La partida de gastos administrativos se encuentra representada principalmente por la carga de personal y por los servicios prestados por terceros.

Los gastos de ventas se encuentran constituidas en su mayoría por la carga del personal que se encarga de comercialización y distribución de la mercadería. Otra cuenta significativa dentro de esta partida son los servicios prestados por terceros en donde se contemplan las comisiones de venta, los transportes, correos y telecomunicaciones entre otros servicios.

\subsubsection{Análisis Horizontal}

A continuación, se realizará un análisis horizontal del Estado de Resultados (Anexo 4) por los períodos culminados del 2015 al 2017, en dónde se encontraron las siguientes observaciones:

Tabla 4.8

Análisis Horizontal del Estado de Resultados - 2015-2017

\begin{tabular}{|c|c|c|c|c|}
\hline & \multicolumn{2}{|c|}{$\begin{array}{c}\text { Análisis Horizontal (Dic } \\
17 \text { - Dic 16) }\end{array}$} & \multicolumn{2}{|c|}{$\begin{array}{c}\text { Análisis Horizontal (Dic } \\
16 \text { - Dic 15) }\end{array}$} \\
\hline & Var. SI. (000) & $\%$ & Var. SI. $(000)$ & $\%$ \\
\hline Ventas & 53,867 & $16.62 \%$ & 4,143 & $-1.26 \%$ \\
\hline Costo de ventas & 58,195 & $24.48 \%$ & 9,072 & $-3.68 \%$ \\
\hline
\end{tabular}

Fuente: Superintendencia del Mercado de Valores. (s. f.a, s.f.b, s.f.c). Elaboración propia

Como se mencionó en el análisis vertical de las cuentas por cobrar comerciales, el 2017 hubo un incremento en las ventas de un 17 \% a comparación del año 2016.

Las ventas dentro del país subieron un $78 \%$ mientras que las ventas al exterior decrecieron en un $5 \%$.

Las ventas dentro del país incrementaron en un porcentaje mayor a años anteriores debido a que la Compañía incremento sus esfuerzos en las operaciones de su línea de negocio SOL ALPACA aprovechando sus canales de distribución en diferentes partes del país como sus tiendas propias y en consignación, así como también en sus ventas al exterior. Reforzaron la venta de sus productos de lana de vicuña (mantas, estolas, chalinas, capas, etc.) dentro del país y en el exterior a través de los canales de venta de SOL ALPACA. 
Como consecuencia del mayor aumento de las ventas también el costo de ventas experimentó un incremento en especial en lo referido al costo de materia prima.

\subsubsection{Ratios Financieros}

\subsubsection{Ratios de Liquidez}

Tabla 4. 9

Detalle de Ratios de Liquidez 2015-2017
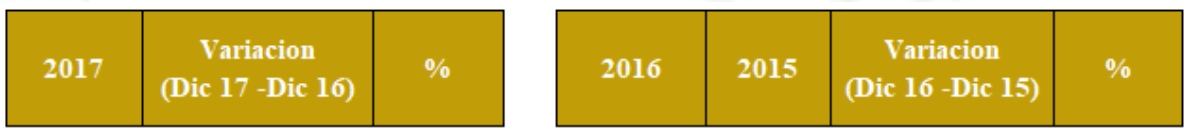

$\underline{\text { Ratios de Liquidez }}$

\begin{tabular}{|l|r|}
\hline Capital de Trabajo & 110,323 \\
\hline Razón corriente & 1.64 \\
\hline Ratio de Prueba acida & 0.57 \\
\hline Ratio de Prueba defensiva & 0.12
\end{tabular}

$$
\begin{aligned}
& -3,333>-2.93 \% \\
& -0.48>-22.60 \% \\
& \begin{array}{r}
-0.09>-13.20 \% \\
-0.01^{\prime}>-8.88 \%
\end{array}
\end{aligned}
$$$$
113,656 \quad 100,858
$$$$
\begin{array}{cc}
2.12 & 2.05 \\
0.65 & 0.76 \\
0.13 & 0.17
\end{array}
$$

$12,797>12.69 \%$

$0.08>3.81 \%$

$-0.11-14.26 \%$

$-0.04-22.29 \%$

Fuente: Superintendencia del Mercado de Valores. (s. f.a, s.f.b, s.f.c).

Elaboración propia

El capital de trabajo nos muestra en qué medida la empresa podrá cumplir con sus deudas en el corto plazo y una vez canceladas estas con cuanto capital contará para poder seguir con sus operaciones del día a día.

En cuanto a la compañía, se puede observar que el capital de trabajo en el 2016 tuvo un aumento, esto debido al aumento de los activos corrientes, específicamente al concepto de inventarios. En el año 2017 también hubo un incremento, pero esta vez debido a la mayor adquisición de materia prima para poder satisfacer la demanda creciente del 2017.

La disminución en el 2017 de la razón corriente nos muestra que la capacidad de pagar sus deudas al corto plazo bajo desde el 2016 al 2017 de 2.12 veces a 1.64 veces, respectivamente. Es decir, que la compañía tiene 0.48 veces menos de activos para cubrir una unidad monetaria de deuda. Esto se debe al mayor aumento de las obligaciones financieras en el período 2017, las cuales se obtuvieron para subsanar las brechas de liquidez originadas por la obtención de materia prima y otros insumos necesarios para la producción mediante préstamos sobre futuras ventas al exterior. 


\subsubsection{Ratios de Solvencia}

Tabla 4. 10

Detalle de Ratios de Solvencia 2015-2017
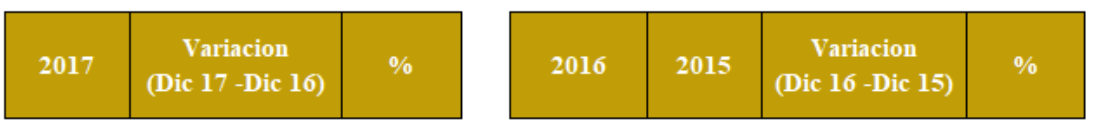

$\underline{\text { Ratios de Solvencia }}$

\begin{tabular}{|l|}
\hline Ratio de deuda \\
\hline Ratio de endeudamiento total \\
\hline Ratio de endeudamiento CP \\
\hline Ratio de cobertura de Gastos Financieros \\
\hline
\end{tabular}

0.40
0.67
0.67
25.95

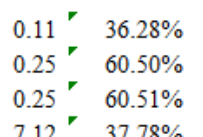

$\begin{array}{rr}0.29^{\prime} & 0.30^{\prime} \\ 0.42 & 0.42^{\prime} \\ 0.42 & 0.42^{\prime} \\ 18.83 & 25.95^{\prime}\end{array}$

$-0.00>-0.93 \%$

$-0.01>-1.31 \%$

$-0.01>-1.32 \%$

$-7.12^{\prime}-27.42 \%$

Fuente: Superintendencia del Mercado de Valores. (s. f.a, s.f.b, s.f.c).

Elaboración propia

Como se mencionó anteriormente el aumento del endeudamiento en el 2017 se debe a que en ese año la empresa se financió de terceros para poder adquirir más materias primas e insumos para satisfacer la demanda.

La capacidad de la Compañía para cumplir con las obligaciones provenientes de sus deudas disminuyó en el 2016 debido a la disminución de las ventas y al aumento de los gastos operativos dando una disminución de las utilidades antes de impuestos de ese mismo año.

Esta situación se regularizó en el 2017 con el incremento de las ventas de ese mismo año, logrando cubrir con estas utilidades los gastos financieros hasta 25.95 veces.

\subsubsection{Ratios de Gestión}

Las ratios de gestión son aquellos indicadores que nos dan un indicio de la eficiencia de la Compañía con respecto a sus operaciones de cobros, pagos y rotación de inventarios. En resumen, mide la eficiencia de la operatividad de la Compañía. 
Tabla 4. 11

Detalle de Ratios de Gestión 2015-2017

\begin{tabular}{|c|c|c|c|c|c|c|c|}
\hline & 2017 & $\begin{array}{c}\text { Variacion } \\
\text { (Dic } 17 \text {-Dic 16) }\end{array}$ & $\%$ & 2016 & 2015 & $\begin{array}{c}\text { Variacion } \\
\text { (Dic } 16-\text { Dic 15) }\end{array}$ & $\%$ \\
\hline \multicolumn{8}{|l|}{$\underline{\text { Ratios de Gestión }}$} \\
\hline Periodo promedio de cobro & 60.76 & $14.43^{\prime}$ & $31.14 \%$ & 46.33 & 51.72 & $-5.39^{\prime}$ & $-10.43 \%$ \\
\hline \begin{tabular}{|l|} 
Periodo promedio de pago \\
\end{tabular} & 19.70 & $4.55^{\prime}$ & $30.08 \%$ & 15.14 & 15.19 & $-0.05^{\prime}$ & $-0.34 \%$ \\
\hline Ciclo Operativo & 288.16 & $13.66^{\prime \prime}$ & $4.97 \%$ & 274.50 & 234.66 & 39.84 & $16.98 \%$ \\
\hline Ciclo de conversión de efectivo & 268.46 & $9.10^{\prime}$ & $3.51 \%$ & 259.36 & 219.47 & $39.89^{\prime}$ & $18.18 \%$ \\
\hline
\end{tabular}

Fuente: Superintendencia del Mercado de Valores. (s. f.a, s.f.b, s.f.c).

Elaboración propia

El aumento del período promedio de cobro se debe al aumento de las cuentas por cobrar comerciales en el 2017, llegando a tener un promedio de 61 días de promedio de cobro; sin embargo, como se mencionan en los estados financieros auditados las cuentas por cobrar comerciales son siempre corrientes es decir que no superan los 90 días, por lo tanto, está dentro de su política de cobro.

Las cuentas por pagar comerciales experimentaron un aumento en el 2017, este aumento se debe en su mayoría al incremento de las compras de materia prima para satisfacer la demanda creciente de ventas. Esto significa que en el 2017 la empresa está aprovechando por 5 días más los créditos otorgados por sus proveedores a comparación del 2016 en donde el promedio período de pago era de 15 días.

Cabe resaltar que la Compañía mantiene altos stocks de materia prima, ya que con esto garantiza la continuidad de sus operaciones. El aumento del período promedio de inventarios significa que las mercaderías de la Compañía están ingresando al mercado cada 228 días lo cual es una baja rotación a comparación del 2015 que era de 183 días. Este resultado está ligado a la caída de las ventas que hubo en el 2016, ya que estas cayeron en un $1.26 \%$ a comparación del año anterior.

El ciclo operativo muestra el recorrido de la mercadería por el activo circulante hasta el recibir el cobro de la misma. Como se puede observar el promedio del ciclo operativo ha ido en aumento desde el 2015 al 2017.

En el 2016, el ciclo operativo aumentó debido al incremento del período promedio de inventarios que está relacionado directamente a la caída de las ventas de ese mismo año. 
En el 2017, la subida en esta ratio se debe al incremento en el período promedio de cobro que como se explicó anteriormente se debe al aumento de las cuentas por cobrar comerciales que están ligadas a la mayor cantidad de ventas que hubo en ese año.

El ciclo de conversión de efectivo nos muestra el número de días que transcurren para que se haga efectivo el cobro de la mercadería. A diferencia del ciclo operativo aquí se considera el período promedio de pago ya que el cobro se hace efectivo a partir del día en que se paga la mercadería.

El ratio de conversión de efectivo ha ido en aumento desde el 2015 al 2017, ya que, si bien es cierto que los días del período promedio de pago aumentaron, no lo hicieron proporcionalmente a los días del período promedio de cobro ni a los días del período promedio de inventario. Es por esto que se puede inferir que la Compañía paga más rápido a sus proveedores de lo que cobra a sus clientes lo cual hace que se vea en la necesidad de pedir préstamos sobre ventas futuras para subsanar esa creciente brecha de liquidez y así financiar sus operaciones cotidianas.

\subsubsection{Ratios de Rentabilidad}

Tabla 4. 12

Detalle de Ratios de Rentabilidad 2015-2017
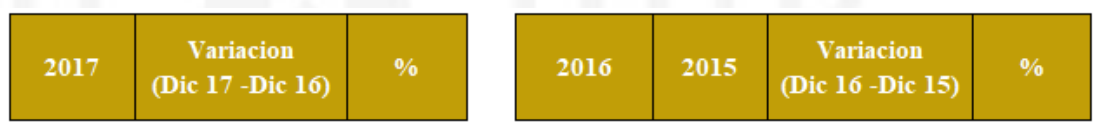

$\underline{\text { Ratios de rentabilidad }}$

\begin{tabular}{|l|}
\hline Rentabilidad de Capital Propio (ROE) \\
\hline Rentabilidad sobre Activos (ROA) \\
\hline Margen Bruto \\
\hline Margen Neto \\
\hline Margen Operativo \\
\hline EBITDA \\
\hline
\end{tabular}

0.11
0.07
0.22
0.08
0.11
49,962

$$
\begin{aligned}
& -0.01>-5.05 \% \\
& -0.02>-19.38 \% \\
& -0.05^{>}-18.56 \% \\
& -0.01>-14.05 \% \\
& -0.02>-17.49 \% \\
& -2,293>-4.39 \%
\end{aligned}
$$

$\begin{array}{cc}0.12 & 0.14^{r} \\ 0.09 & 0.10^{r} \\ 0.27 & 0.25^{r} \\ 0.09 & 0.10^{r} \\ 0.13 & 0.14 \\ 52,255 & 54,308\end{array}$

$$
\begin{aligned}
& -0.02>-11.86 \% \\
& -0.01>-11.51 \% \\
& 0.02>7.42 \% \\
& -0.00>-5.12 \% \\
& -0.00>-3.64 \% \\
& -2,053>-3.93 \%
\end{aligned}
$$

Fuente: Superintendencia del Mercado de Valores. (s. f.a, s.f.b, s.f.c).

Elaboración propia

Con el ROE podemos medir la rentabilidad que obtiene el inversionista sobre los fondos aportados al patrimonio.

Si bien las ventas aumentaron desde el 2015 al 2017, también lo hicieron los gastos operativos dando como resultado una disminución en la utilidad neta de esos períodos. En resumen, se puede observar que la disminución de la utilidad neta de cada 
año es proporcional a la disminución de la rentabilidad sobre el patrimonio de cada uno de ellos.

Con el ratio de ROA sirve para medir la eficacia de la administración y su producción de beneficios sobre los activos disponibles de la Compañía.

Como se mencionó anteriormente hubo una disminución de la utilidad neta desde el 2015 al 2017, esto no solo afecto la rentabilidad sobre el patrimonio sino también la rentabilidad sobre los activos totales generando un $2 \%$ menos de rentabilidad que el 2016 y un $3 \%$ menos a comparación del 2015.

En el caso del EBITDA se puede observar una disminución a pesar del incremento de las ventas de dichos años, esto se debe al aumento del costo de ventas a comparación de los años anteriores. La mayor variación dentro del costo de ventas es ocasionada por el alza de los precios de las materias primas e insumos utilizados, consecuencia derivada de los efectos medioambientales del Fenómeno del Niño.

\subsection{Proyecciones}

\subsubsection{Estado de resultados (Anexo 5)}

Se procedió a hacer las proyecciones del Estado de Resultados de los años 2018 al 2020 basándose en la información histórica de los períodos culminados del 2015 al 2017.

\subsubsection{Supuestos}

Para las presentes proyecciones se tomaron en cuenta los siguientes supuestos:

1. En el caso de las ventas se tomó en cuenta el crecimiento anual del PBI, el crecimiento anual del PBI del Sector Económico y el crecimiento anual de las exportaciones, en específico del sector textil. Dichos datos fueron escogidos de las Proyecciones Económicas Multianuales (2018 al 2020) que fueron aprobadas el 23 de agosto del 2017.

El crecimiento anual proyectado del PBI se determinó en base a tres etapas, siendo la primera etapa que se da en el segundo semestre del 2017 donde inicia el crecimiento acelerado de la economía peruana gracias al proceso de reconstrucción y a los trabajos de infraestructura para la preparación de los Juegos Panamericanos. La segunda etapa que inicia en el 2018 se observa una 
mejora gradual de la inversión privada en consecuencia de una mayor demanda interna, así como del alza de los precios de los metales y el desarrollo de proyectos importantes de infraestructura que buscan incentivar la inversión minera.

En la tercera fase que comprende desde el 2019 al 2021 se estima que la tasa de crecimiento se consolidará en un $4 \%$ gracias al aumento de la inversión en infraestructura, en el sector de hidrocarburos y minero. En paralelo, también se estima una mayor contratación formal y la consolidación de un entorno de negocios favorables impulsados por la eliminación de barreras burocráticas, el retiro gradual del impulso fiscal y la simplificación administrativa (Ministerio de Economía y Finanzas [MEF], 2017).

Tabla 4.13

Variación porcentual de la Demanda Interna y el PBI (Var. \% real anual)

\begin{tabular}{lcrrrc}
\hline & $\begin{array}{r}\text { Estructura \% } \\
\text { del PBI 2016 }\end{array}$ & 2016 & 2017 & 2018 & $\begin{array}{c}\text { Prom } \\
2019-2021\end{array}$ \\
\hline I. Demanda interna & 100,0 & 1,0 & 0,9 & 3,6 & 4,0 \\
1. Gasto privado & 82,3 & 1,3 & 1,3 & 3,0 & 4,1 \\
a. Consumo privado & 65,2 & 3,4 & 2,3 & 2,8 & 3,9 \\
b. Inversión privada & 17,8 & $-5,9$ & $-2,3$ & 3,5 & 5,0 \\
2. Gasto público & 16,9 & $-0,2$ & 2,5 & 8,7 & 2,6 \\
a. Consumo público & 12,1 & $-0,5$ & 0,5 & 5,0 & 2,0 \\
b. Inversión pública & 4,8 & 0,6 & 7,5 & 17,5 & 3,8 \\
i. Inv. pública sin reconstrucción & - & - & - & $-7,3$ & 12,4 \\
II. Demanda externa neta & & & & & \\
1. Exportaciones ${ }^{1}$ & 22,2 & 9,5 & 8,8 & 4,8 & 4,0 \\
a. Tradicionales & 13,4 & 16,6 & 9,1 & 4,6 & 2,4 \\
b. No tradicionales & 5,5 & 0,9 & 3,0 & 4,1 & 5,9 \\
2. Importaciones ${ }^{1}$ & 22,2 & $-2,2$ & 1,9 & 3,5 & 4,1 \\
III. PBI & 100,0 & 4,0 & 2,8 & 4,0 & 4,0 \\
\hline
\end{tabular}

Fuente: Ministerio de Economía y Finanzas (2017)

Dado que el giro comercial de Michell \& Cía. S.A., este se encuentra dentro del crecimiento del sector económico de Manufactura no primaria el cual se estima que crecerá en un $3.7 \%$ para los períodos 2018-2021 
Tabla 4. 14

Variación porcentual del PBI por sectores económicos (Var. \% real anual)

\begin{tabular}{|c|c|c|c|c|c|}
\hline & $\begin{array}{l}\text { Peso Año } \\
\text { Base } 2007\end{array}$ & 2016 & 2017 & 2018 & $\begin{array}{c}\text { Prom } \\
2019-2021\end{array}$ \\
\hline Agropecuario & 6,0 & 2,3 & 0,9 & 4,6 & 4,0 \\
\hline Agrícola & 3,8 & 1,4 & $-0,5$ & 4,9 & 3,9 \\
\hline Pecuario & 2,2 & 3,7 & 3,0 & 4,2 & 4,2 \\
\hline Pesca & 0,7 & $-10,1$ & 34,7 & 5,4 & 3,5 \\
\hline Minería e hidrocarburos & 14,4 & 16,3 & 4,9 & 4,7 & 1,7 \\
\hline Minería metálica & 12,1 & 21,1 & 5,5 & 4,1 & 2,1 \\
\hline Hidrocarburos & 2,2 & $-5,1$ & 2,4 & 7,2 & 0,0 \\
\hline Manufactura & 16,5 & $-1,4$ & 1,4 & 3,4 & 3,6 \\
\hline Primaria & 4,1 & $-0,6$ & 9,7 & 3,6 & 3,2 \\
\hline No primaria & 12,4 & $-1,7$ & $-0,6$ & 3,3 & 3,7 \\
\hline Electricidad y agua & 1,7 & 7,3 & 3,2 & 5,0 & 5,5 \\
\hline Construcción & 5,1 & $-3,1$ & $-0,1$ & 8,8 & 5,3 \\
\hline Comercio & 10,2 & 1,8 & 1,6 & 2,5 & 4,0 \\
\hline Servicios & 37,1 & 4,3 & 3,1 & 3,7 & 4,8 \\
\hline PBI & 100,0 & 4,0 & 2,8 & 4,0 & 4,0 \\
\hline PBI primario & 25,2 & 9,9 & 5,0 & 4,6 & 2,4 \\
\hline PBI no primario ${ }^{2}$ & 66,5 & 2,4 & 2,1 & 4,0 & 4,6 \\
\hline
\end{tabular}

Fuente: Ministerio de Economía y Finanzas (2017)

Y por último el crecimiento de las exportaciones se estima que crecerá a un ritmo de $3.2 \%$ en el sector textil, sector que considera dentro de las Exportaciones No Tradicionales. Cabe resaltar que las ventas al exterior del país en Michell \& Cía. S.A. conforman casi el $70 \%$ de sus ventas anuales.

Figura 4. 1

Proyección de las exportaciones no tradicionales 2018-2021 (Var. Anual promedio)

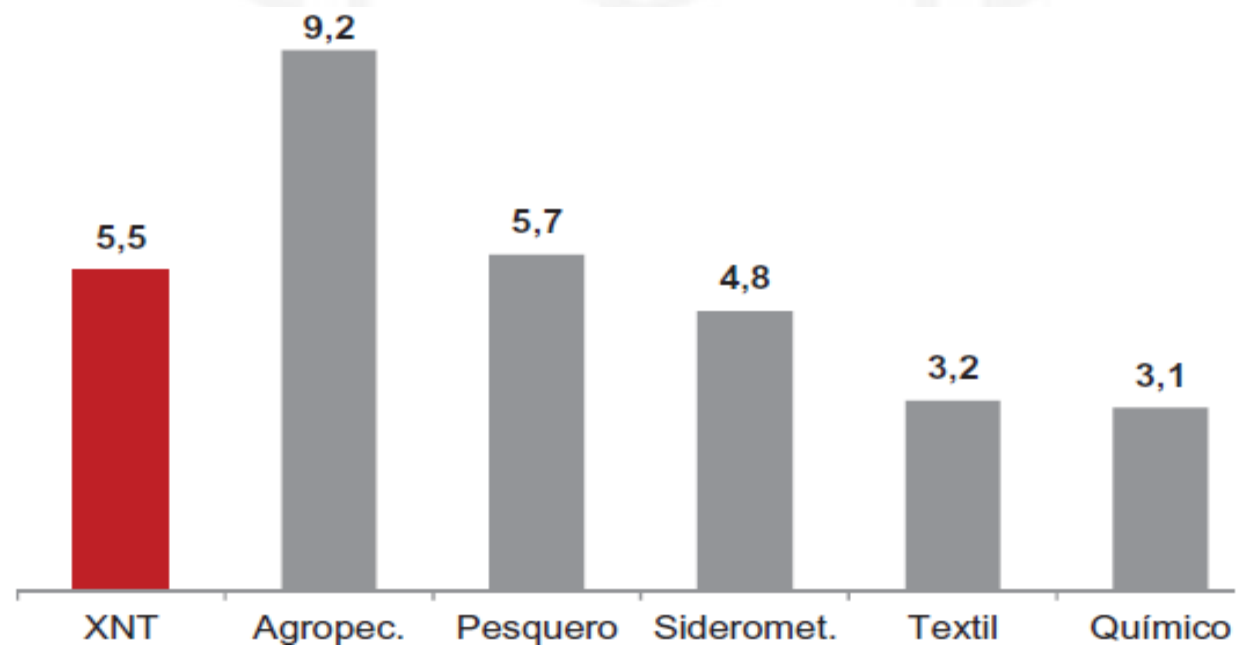

Fuente: Banco Central de Reserva del Perú (2017) 
En base a lo expuesto, las ventas se proyectarán a una tasa de crecimiento del $3.6 \%$ tomando como base las ventas del 2017:

Tabla 4. 15

Supuestos para proyección de ventas 2018-2020

\begin{tabular}{|l|c|}
\hline & $\%$ \\
\hline PBI & $4.00 \%$ \\
\hline PBI Manufactura No Primaria & $3.70 \%$ \\
\hline $\begin{array}{l}\text { Crecimiento de exportaciones (Sector } \\
\text { Textil) }\end{array}$ & $3.20 \%$ \\
\hline Tasa de crecimiento proyectado & $\mathbf{3 . 6 0 \%}$ \\
\hline
\end{tabular}

Fuente: Ministerio de Economía y Finanzas (2017)

Elaboración propia

Siendo las ventas proyectadas del 2018-2020 las siguientes:

Tabla 4. 16

Ventas proyectadas 2018-2020

\begin{tabular}{|l|c|c|c|}
\hline & $\mathbf{2 0 2 0}$ S/. (000) & 2019 S/. (000) & 2018 S/. (000) \\
\hline Ventas & 418,998 & 404,829 & 391,139 \\
\hline
\end{tabular}

Fuente: Ministerio de Economía y Finanzas (2017)

Elaboración propia

2. En el Costo de Ventas se proyectará en base al análisis realizado en el Ratio de Margen Bruto de los años 2015 al 2017 donde se puede observar lo siguiente: 
Tabla 4. 17

Detalle del Margen Bruto 2015-2017

\begin{tabular}{|c|c|}
\hline Período & Margen Bruto \\
\hline 2015 & $24.79 \%$ \\
\hline 2016 & $26.62 \%$ \\
\hline 2017 & $21.68 \%$ \\
\hline Tasa de Proyección (2018-2020) & $\mathbf{2 4 . 0 0 \%}$ \\
\hline
\end{tabular}

Fuente: Ministerio de Economía y Finanzas (2017)

Elaboración propia

Por lo tanto, dicho porcentaje (24\%) de Margen Bruto se utilizará como base para la proyección del costo de ventas del 2018 al 2020. Con esta ratio se podrá proyectar la Utilidad bruta de estos períodos y por ende el costo de ventas. Además, se puede observar en el Análisis de Vertical del Costo de Ventas que este se ha mantenido en una tendencia constante del 2015 al 2017, llegando a ser en promedio el $75 \%$ de las ventas lo cual afirma la tendencia constante de crecimiento del costo de ventas.

En resumen, se obtiene que el Costo de Ventas proyectado para los períodos 20182020 serían los siguientes:

Tabla 4. 18

Detalle del Margen Bruto 2015-2017

\begin{tabular}{|l|c|c|c|}
\hline & $\mathbf{2 0 2 0}$ S/. (000) & $\mathbf{2 0 1 9}$ S/. (000) & $\mathbf{2 0 1 8 ~ S / . ~ ( 0 0 0 ) ~}$ \\
\hline Ventas & 418,998 & 404,829 & 391,139 \\
\hline Costo de Ventas & $(318,439)$ & $(307,670)$ & $(297,266)$ \\
\hline Utilidad Bruta & $\mathbf{1 0 0 , 5 6 0}$ & $\mathbf{9 7 , 1 5 9}$ & $\mathbf{9 3 , 8 7 3}$ \\
\hline
\end{tabular}

Fuente: Ministerio de Economía y Finanzas (2017).

Elaboración propia

3. Para las demás cuentas del Estado de Resultados se observó que las variaciones en Análisis Horizontal han mantenido una tendencia constante, 
por lo tanto, se proyectaron en base a un promedio del Análisis Vertical de los períodos culminados del 2015-2017.

4. Para las demás cuentas del Estado de Resultados se pudo observar en el Análisis Horizontal que la variación en los períodos culminados de los años 2015-2017 no ha sido significativa, por lo tanto, se proyectarán dichas cuentas en base al promedio del Análisis Vertical de dichos períodos.

\subsubsection{Estado de Situación Financiera (Anexo 6)}

Se procedió a hacer las proyecciones del Estado de situación Financiera del 2018 al 2020 basándose en la información histórica de los períodos culminados de los años del 20152017.

\subsubsection{Supuestos}

- El Total de Activos se proyectó en base al porcentaje del crecimiento de las ventas de los Estados de Resultados proyectados del 2018 al 2020.

- El Activo Corriente, el Activo no Corriente, el Pasivo Corriente y el Pasivo no corriente se proyectaron en base al promedio del Análisis Vertical de los períodos culminado del 2015 al 2017.

- En la cuenta de Patrimonio las Partidas de Capital Emitido, Acciones de Inversión, Excedente de Revaluación y Otras Reservas de Patrimonio se mantienen constantes para las proyecciones del 2018 al 2020, ya que dicha tendencia se mantuvo en los períodos anteriores del 2015 al 2017.

La única partida del Patrimonio que varió y que se proyectó fueron los Resultados Acumulados. Para dicha proyección se sumó la Utilidad Neta del ejercicio 2018 a los Resultados Acumulados del 2017 y se descontó el pago de dividendos del 2018. Cabe resaltar que para la proyección del pago de dividendos de los períodos 2018 al 2020 se halló en base al promedio ponderado entre el pago de dividendos y la utilidad neta de los 
períodos 2015 al 2017, dicho ratio fue multiplicado por las utilidades netas proyectadas de los 3 períodos subsiguientes para el pago de los dividendos proyectados.

\subsubsection{Ratios Financieros 2018-2020 (Anexo 7)}

La proyección de los ratios financieros se hizo en base a los estados financieros proyectados del 2018-2020.

En el caso del EBITDA se proyectó la depreciación y amortización usando el 10\% de Propiedad, planta y equipo bruto, se escogió el $10 \%$ ya que maquinaria y equipo representaban en su mayoría más del $50 \%$ de la cuenta.

Por los demás ratios se asumió un crecimiento constante según las proyecciones de los Estados Financieros Proyectados de la Compañía.

Para ver mayor detalle de las Proyecciones de los Ratios Financieros 2018-2020 sírvase ver el Anexo 7.

\subsection{Implementación de las nuevas normas}

\subsubsection{NIIF 9: Instrumentos Financieros}

Michell \& Cía. S.A. al no ser una entidad financiera adoptará el método simplificado. Para lo cual se evaluará la información histórica que refleje las condiciones actuales y las características del entorno.

Se seleccionaron los siguientes períodos: 31/12/2013, 31/12/2014, 31/12/2015 y $31 / 12 / 2016$.

Finalmente, bajo este método el ratio de pérdida esperada no variaría significativamente con la provisión que mantiene la Compañía en el 2017, por lo tanto se concluye que la implementación de dicha norma no impactará de manera significativa los estados financieros de la Compañía por los períodos posteriores al 2017.

\subsubsection{NIIF 16: Arrendamientos}

La Compañía no mantiene arrendamientos operativos ni financieros al cierre del 2017. Por lo que la implementación de esta norma no tendrá ningún impacto. 


\section{CAPÍTULO 5: CONCLUSIONES Y RECOMENDACIONES}

\subsection{Conclusiones}

1. El análisis financiero realizado evidenció la importancia de la misma para la toma de decisiones ya que permite plantear estrategias según el modelo de negocio que ayuden a maximizar el valor de la Compañía y a mejorar la optimización de los procesos. Además, también hemos podido observar que el análisis financiero permite generar medidas que puedan amortiguar o monitorear el impacto de los sucesos que están fuera del control de la Compañía.

2. De manera más específica se puede observar lo siguiente:

A. En el ratio de conversión de efectivo se puede observar que sale en promedio 250 días por los períodos del 2015-2017 lo que significa que la Compañía necesita financiarse durante dichos días hasta que pueda cobrar la venta. Para resolver dicha situación la Compañía ha optado por financiarse mediante préstamos sobre ventas futuras para poder continuar con sus operaciones del día a día.

B. En la cuenta de Propiedad, Planta y Equipo se puede observar un aumento de la inversión en Maquinarias y Equipos por los períodos del 2015 al 2017. Cabe resaltar que dichos fondos provienen de las ventas del propio giro del negocio. Esta decisión se puede apreciar en el aumento de las ventas de los años 2015-2017 y en la percepción mundial que se tiene sobre la calidad de los productos de la Compañía, además que es considerada una de las empresas líderes del sector.

\subsection{Recomendaciones}

1. Se recomienda que la Compañía realice un análisis financiero trimestral de los Estados Financieros y de los Ratios Financieros para evaluar el desempeño de la Compañía a lo largo del año. Además, también sería beneficioso que la Compañía 
realice proyecciones de los mismos para monitorear la situación financiera futura de la Compañía y plantear estrategias adecuadas para ella.

2. De manera específica se recomienda lo siguiente:

A. Se recomienda que la compañía debería revaluar su estrategia de penetración de mercado para reducir su período promedio de inventarios y que sus mercaderías circulen más veces por el mercado.

Además, se recomienda evaluar sus políticas de cobro y pago ya que eso les genera un desfase de liquidez que tiene que ser solventado con préstamos bancarios, específicamente reduciendo su período promedio de cobro y aumentando su período promedio de pago.

B. Si bien la compañía se encuentra invirtiendo en Propiedad, Planta y Equipo para aumentar sus ventas, es necesario que la Compañía revalúe su plan de inversión en base al Margen Bruto ya que en los períodos evaluados del 2015-2017 se observa un aumento de las ventas, pero una disminución del margen bruto debido a un aumento de los costos de ventas, por consiguiente, a mayor inversión de la Propiedad, Planta y Equipo generará un mayor aumento en el gasto de depreciación inflando así el costo de ventas. 


\section{REFERENCIAS}

Adot, O. G. (2010). Industrialización a la industrialización de la lana y fibras especiales. Córdoba: Universidad de Católica de Córdoba.

Banco Central de Reserva del Perú. (2017). Memoria 2017. Recuperado de http://www.bcrp.gob.pe/docs/Publicaciones/Memoria/2017/memoria-bcrp2017.pdf

Michell \& Cía S.A. (s. f.). Michell y Cía. Recuperado de http://www.michell.com.pe/michell_acerca_de_michell

Michell \& Cía S.A. (2018). Memoria Anual 2017. Arequipa: Michell \& Cía S.A.

Ministerio de Economía y Finanzas. (2017). Marco macroeconómico multianual 20182021. Lima: Autor.

Rodriguez, A., Valdivia, D., \& Velazco, J. (2018). Planeamiento estratégico para la industria arequipeña textil de fibra de Alpaca. Lima: Pontificia Universidad Católica del Perú.

Superintendencia del Mercado de Valores. (s. f.a). Estados de situación financiera Michell y CIA. S. A. al 31 de diciembre 2015. Recuperado http://www.smv.gob.pe/Bp_InformacionFinanciera?op=bq11

Superintendencia del Mercado de Valores. (s. f.b). Estados de situación financiera Michell y CIA. S. A. al 31 de diciembre 2016. Recuperado http://www.smv.gob.pe/Bp_InformacionFinanciera?op=bq11

Superintendencia del Mercado de Valores. (s. f.c). Estados de situación financiera Michell y CIA. S. A. al 31 de diciembre 2017. Recuperado http://www.smv.gob.pe/Bp_InformacionFinanciera?op=bq11 
ANEXOS 


\section{Anexo 1: Análisis Vertical del estado de Situación Financiera 2015-2017}

Activos

Activos corrientes

Efectivo y equivalentes de efectivo

Cuentas por cobrar comerciales

Otras cuentas por cobrar

Cuentas por cobrar a relacionadas

Existencias, neto

Total activos corrientes
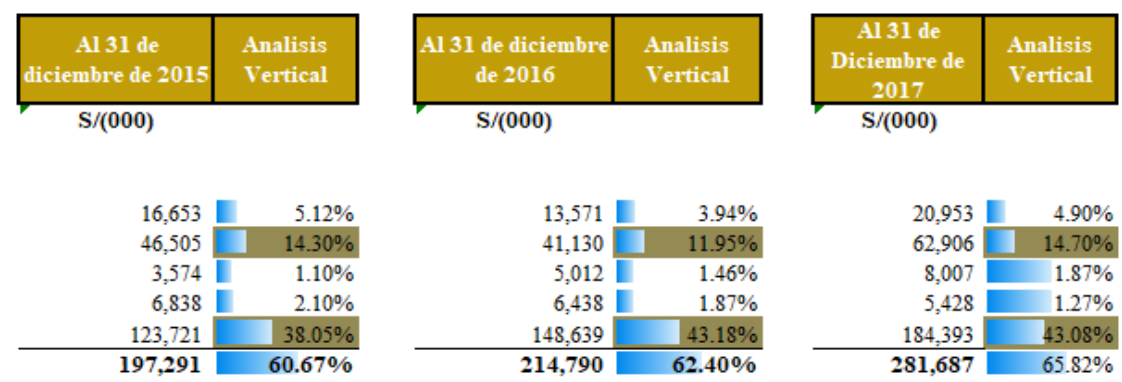

Activos no corrientes

Inventario

Otros activos financieros

Propiedad, planta y equipo, neto

Intangibles

Activo por impuestos a la Ganancia

Diferido

Total activos no corrientes
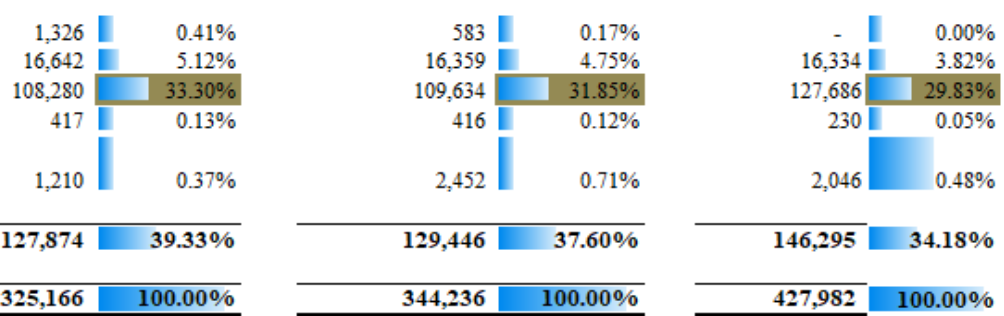

Total de activos

\begin{tabular}{ll}
325,166 & $100.00 \%$ \\
\hline
\end{tabular}

Pasivos y patrimonio

Pasivo corriente

Obligaciones Financieras

Cuentas por pagar comerciales

Otras cuentas por pagar

Cuentas por pagar a relacionadas

Total pasivo corriente

Pasivo no corriente

Otros pasivos diferidos

Total pasivos no corrientes

Total de pasivos

Patrimonio

Capital emitido

Acciones de inversión

Excedente de revaluación

Otras reservas de patrimonio

Resultados acumulados

Total Patrimonio

Total pasivos y patrimonio
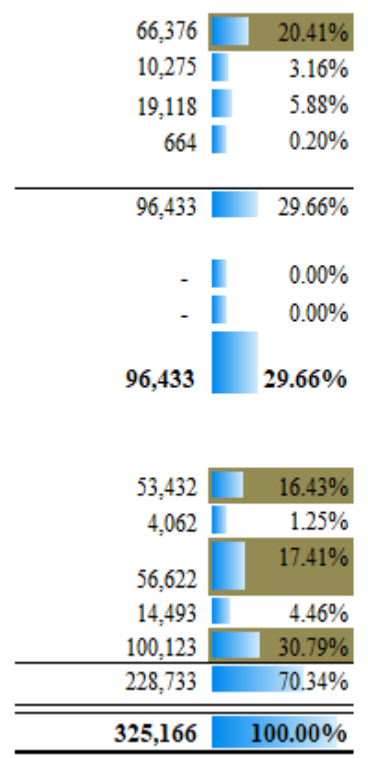
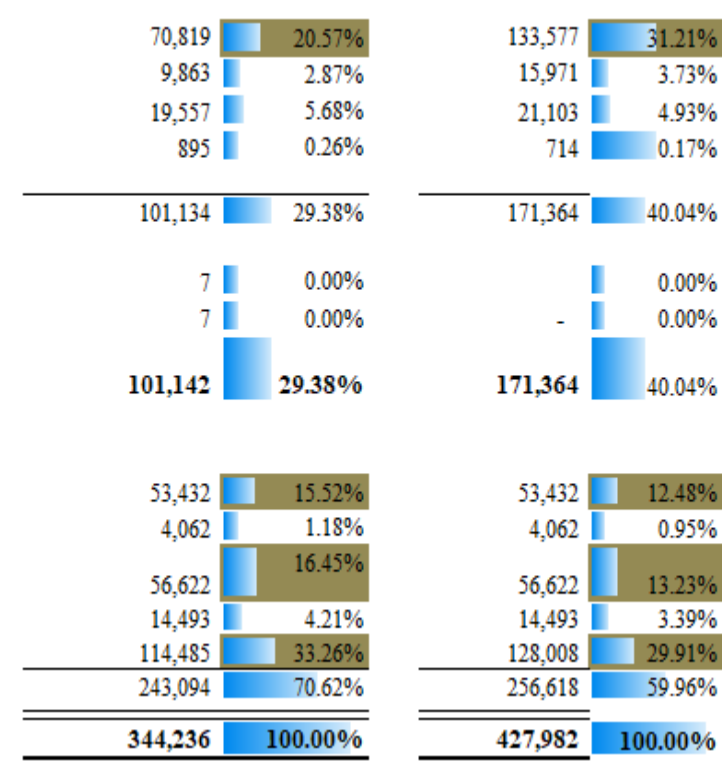


\section{Anexo 2: Análisis Horizontal del estado de Situación Financiera 2015-2017}

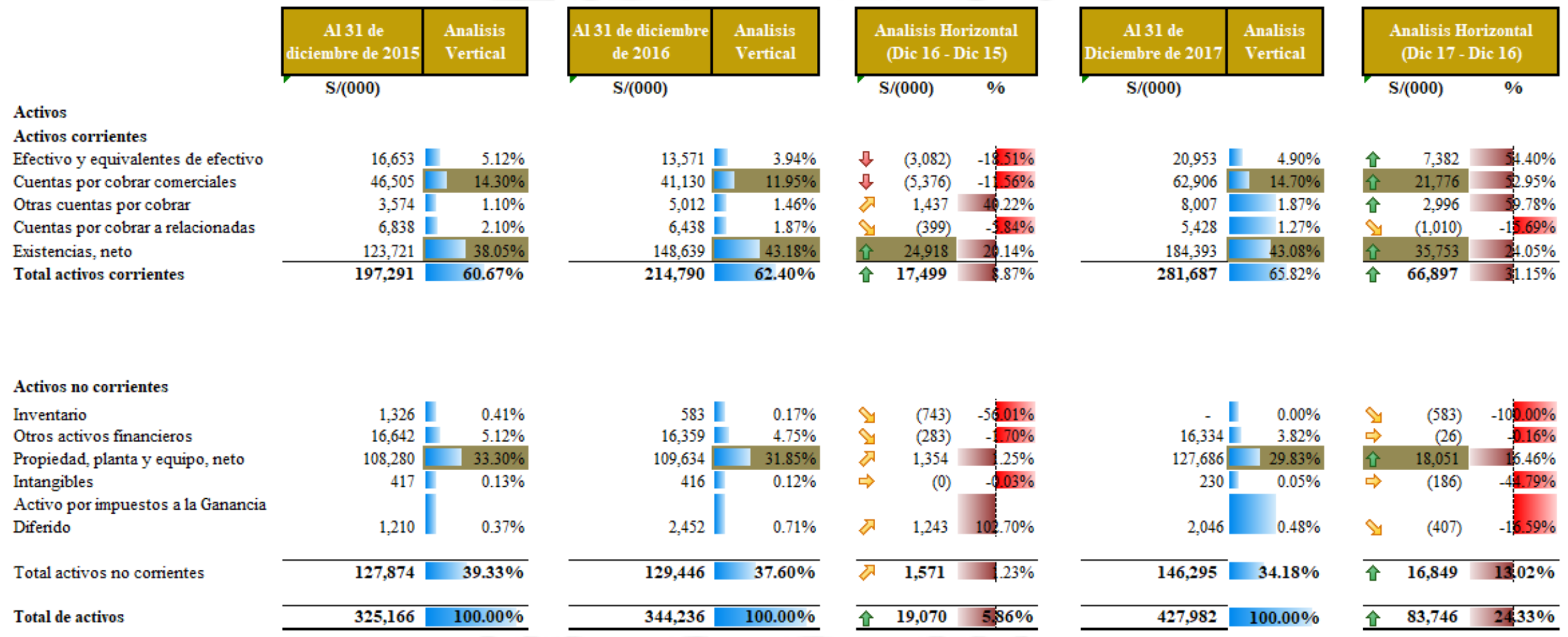




\section{Pasivos y patrimonio}

Pasivo corriente

Obligaciones Financieras

Cuentas por pagar comerciales

Otras cuentas por pagar

Cuentas por pagar a relacionada

Total pasivo corriente

Pasiro no corriente

Otros pasivos diferido

Total pasivos no corrientes

Total de pasivos

Patrimonio

Capital emitido

Acciones de inversión

Excedente de revaluación

Otras reservas de patrimoni

Resultados acumulados

Total Patrimonio

Total pasivos y patrimonio

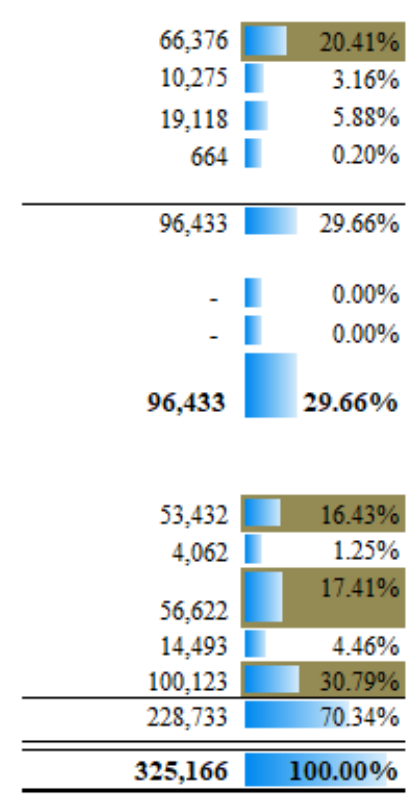

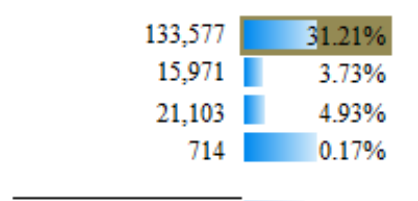

$171,364-40.04 \%$

I $0.00 \%$

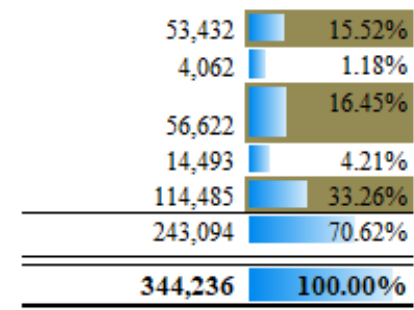

$\begin{array}{ll}4,709 & 48 \%\end{array}$

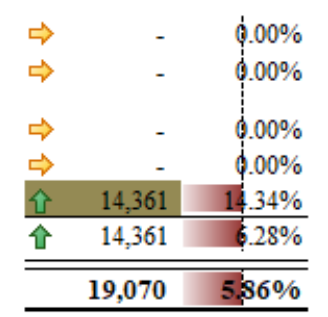

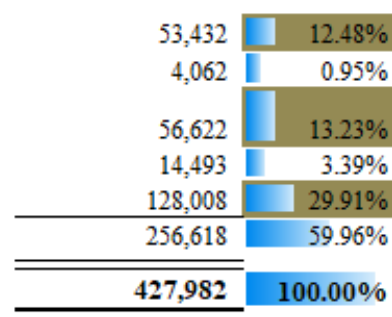


Anexo 3: Análisis Vertical del Estado de Resultados 2015-2017

Ventas

Costo de ventas

Utilidad bruta

Ingresos (gastos) operattvos

Gastos administrativos

Gastos de ventas

Ingresos diversos

Otros gastos diversos

Total de ingresos (gastos), neto

Utilidad operativa

Otros ingresos (gastos)

Ingresos firancieros

Gastos financieros

(Garancia)P é rdida neta por diferencia en cambio

Total de otros gastos, neto

Utilidad antes de impuesto a la renta

Impuesto a la renta

Utilıdad neta de operaciones continuas

\begin{tabular}{|c|c|}
\hline $\begin{array}{c}\text { A131 de diciembre } \\
\text { de 2015 }\end{array}$ & $\begin{array}{c}\text { Aralists } \\
\text { Vertical }\end{array}$ \\
\hline S/(000) & $\%$
\end{tabular}

\begin{tabular}{r|r}
328,188 & $100.00 \%$ \\
$(246,845)$ & $-75.21 \%$ \\
\hline $\mathbf{8 1 , 3 4 3}$ & $\mathbf{2 4 . 7 9 \%}$ \\
\hline
\end{tabular}
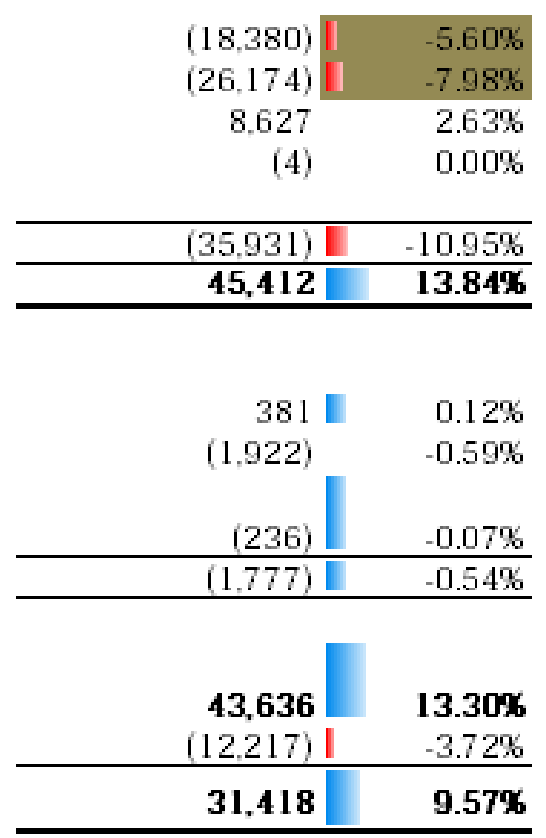

Otros resultados integrales Utilıdad neta

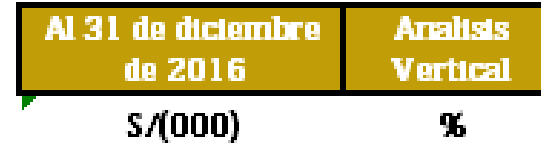

\%

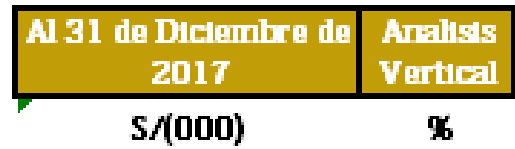

\begin{tabular}{r|r}
324,045 & $100.00 \%$ \\
$(237,773)$ & $-73.38 \%$ \\
\hline $\mathbf{8 6 , 2 7 3}$ & $\mathbf{2 6 . 6 2 \%}$ \\
\hline
\end{tabular}

$377.913 \quad 100.00 \%$ \begin{tabular}{ll|l}
\hline 295,968$)$ & $-78.32 \%$ \\
\hline
\end{tabular}

$81,945 \quad 21.68 \%$

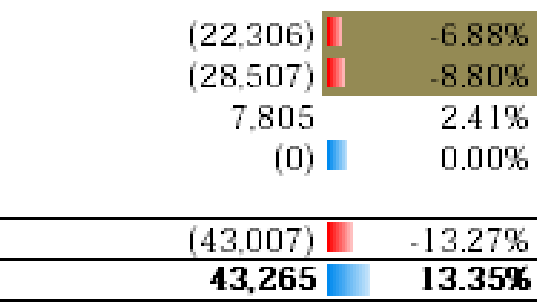

$(17,820) \mid-4.729$

$(31,196) \| \quad-8.25 \%$

$8.701 \quad 2.30 \%$

0 I $0.00 \%$

(40,314) 【-10.67\% $41,63111.02 \%$

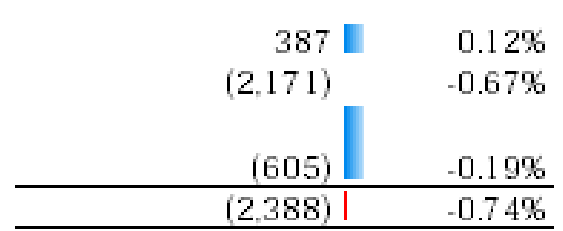

$419 \sqrt{0.110}$

$(1.613) \quad-0.43 \%$

$1.409 \quad 0.37 \%$

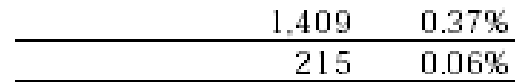

41,846 $11.07 \%$ (12.345) $\quad 3.27 \%$

\begin{tabular}{ll}
$29,501 \quad 7.81 \%$ \\
\hline
\end{tabular}

$29,432 \quad 9.08 \%$

\begin{tabular}{rr}
0 & $0.00 \%$ \\
\hline $\mathbf{2 9 , 4 3 2}$ & $\mathbf{9 . 0 8 \%}$
\end{tabular}




\section{Anexo 4: Análisis Horizontal del Estado de Resultados 2015-2017}

Ventas

Costo de ventas

Utilidad bruta

Ingresos (pastos) operattvos

Gastos administrativ os

Gastos de ventas

Ingresos diversos

otros gastos diversos

Total de ingresos (gastos), neto

Utilldad operattva
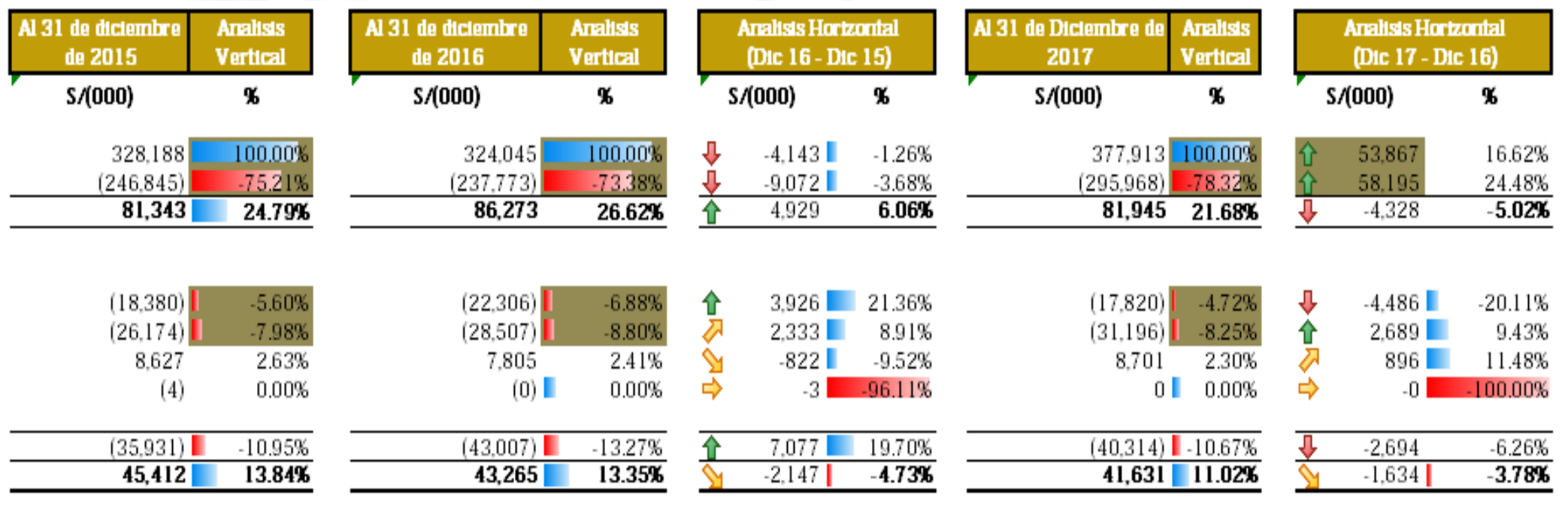

\section{Otros ingresos (gastos)}

Ingresos firancieros

Gastos firancieros

(Garancia)P é rdida neta por diferencia en

cambio

Total de otros gastos, neto
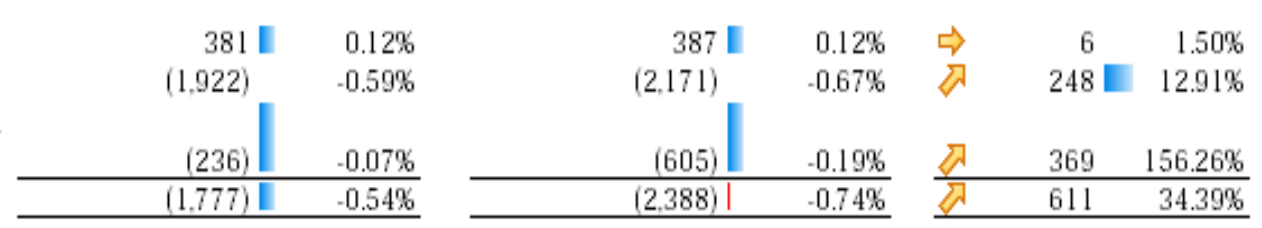

Utilidad antes de impuesto a la renta Impuesto a la renta

Utilldad neta de operaciones continuas

\begin{tabular}{r|r}
$\mathbf{4 3 , 6 3 6}$ & $\mathbf{1 3 . 3 0 \%}$ \\
$(12,217)$ & $-3.72 \%$ \\
\hline $\mathbf{3 1 , 4 1 8}$ & $\mathbf{9 . 5 7 \%}$ \\
\hline
\end{tabular}

\begin{tabular}{rr}
$\mathbf{4 0 , 8 7 7}$ & $\mathbf{1 2 . 6 1 \%}$ \\
$(11,446)$ & $-3.53 \%$ \\
\hline $\mathbf{2 9 , 4 3 2}$ & $\mathbf{9 . 0 8 \%}$ \\
\hline
\end{tabular}

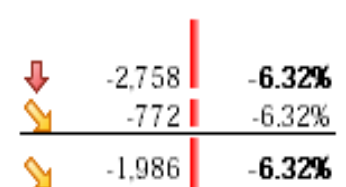

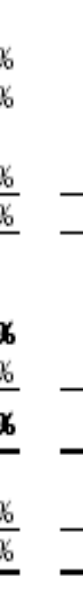

\begin{tabular}{|c|c|}
\hline $\begin{array}{c}419 \text { I } \\
(1,613)\end{array}$ & $\begin{array}{r}0.11 \% \\
-0.43 \%\end{array}$ \\
\hline 1,409 & $0.37 \%$ \\
\hline 215 & $0.06 \%$ \\
\hline $\begin{array}{r}\mathbf{4 1 , 8 4 6} \\
(12,345) \mid \\
\end{array}$ & $\begin{array}{r}11.07 \% \\
-3.27 \% \\
\end{array}$ \\
\hline 29,501 & $7.81 \%$ \\
\hline 01 & $0.00 \%$ \\
\hline 29,501 & $7.81 \%$ \\
\hline
\end{tabular}

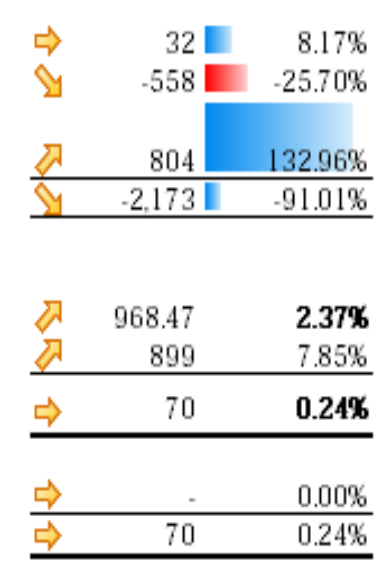


Anexo 5: Proyección del Estado de Resultados 2018-2020
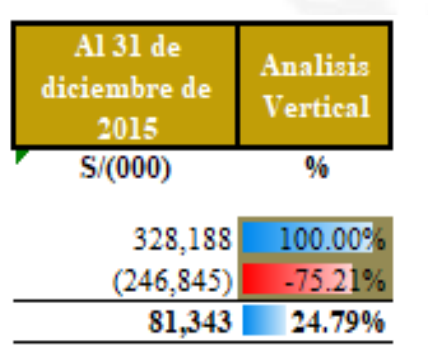

Costo de ventas

Utilidad bruta

Ingresos (gastos) operativos

Gastos administrativos

Gastos de ventas

Ingresos diversos

Otros gastos diversos

Total de ingresos (gastos), neto

Utilidad operativa

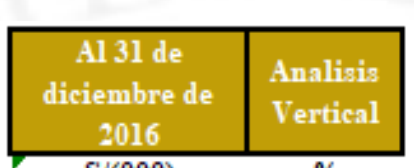

$\mathrm{S} /(000)$
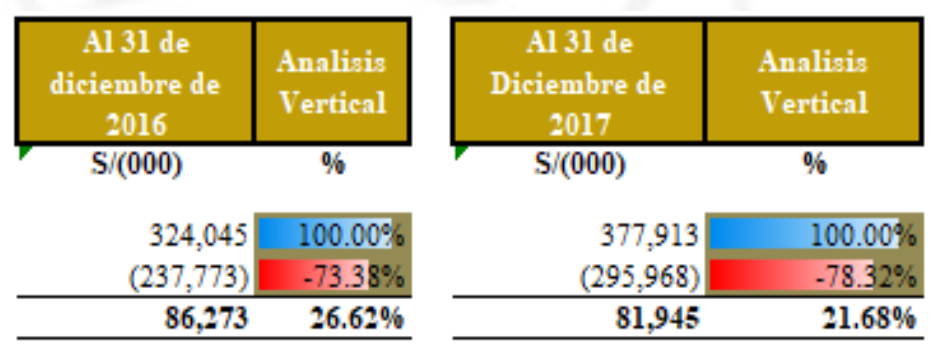

$\%$
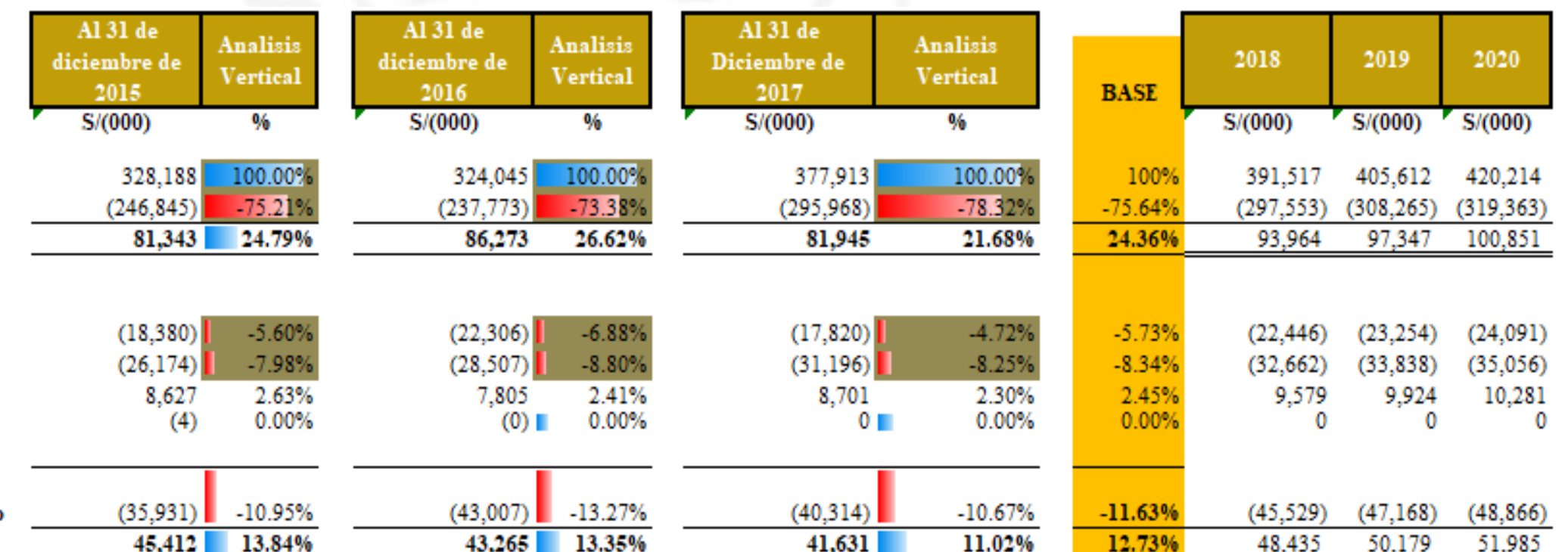

$43,265 \quad 13.35 \%$

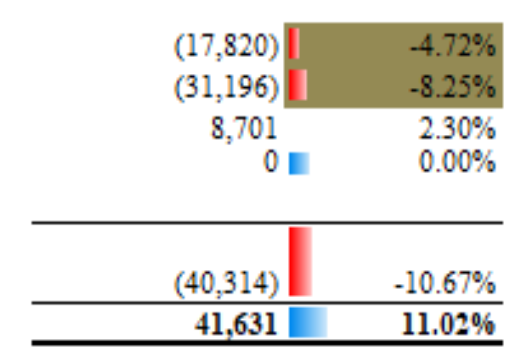

Otros ingresos (gastos)

Ingresos financieros

Gastos financieros

(Ganancia)Pérdida neta por

diferencia en cambio

Total de otros gastos, neto
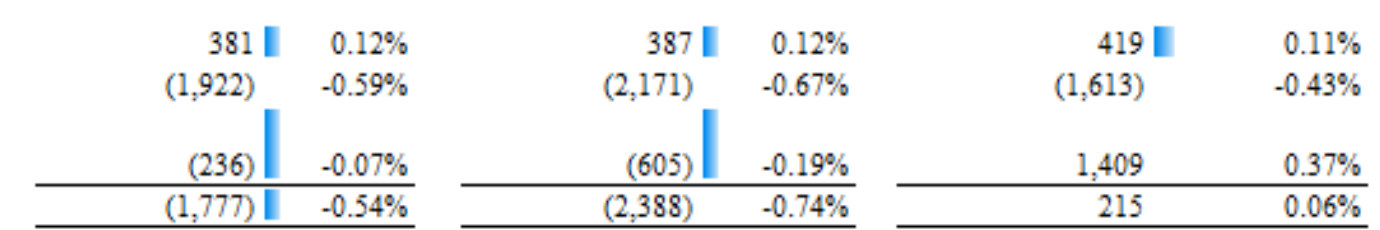

(1)

Utilidad antes de impuesto a la

renta

Impvesto a la renta

Utilidad neta

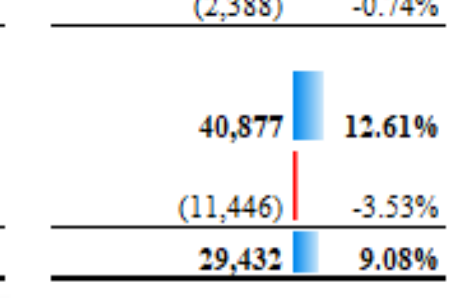

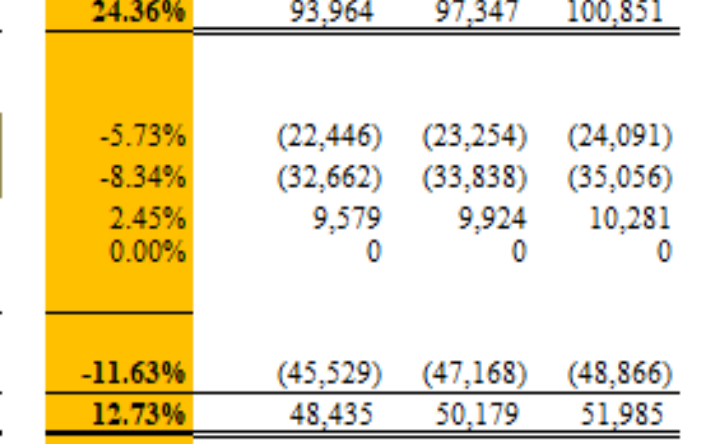

\begin{tabular}{llll}
\hline $\mathbf{1 2 . 7 3} \%$ & 48,435 & 50,179 & 51,985 \\
\hline
\end{tabular}

\begin{tabular}{rrrr}
$0.12 \%$ & 452 & 469 & 485 \\
$-0.56 \%$ & $(2,196)$ & $(2,275)$ & $(2,356)$ \\
& & & \\
$0.04 \%$ & 149 & 154 & 160 \\
\hline$-0.41 \%$ & $(1,594)$ & $(1,652)$ & $(1,711)$ \\
\hline
\end{tabular}

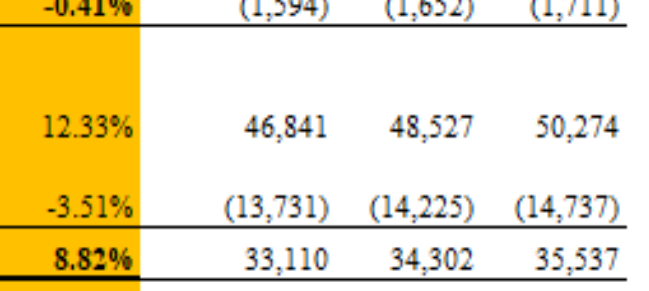




\section{Anexo 6: Proyección del Estado de Situación Financiera 2018-2020}

Activos

Activos corrientes

Efectivo y equivalentes de efectivo

Cuentas por cobrar comerciales

Otras cuentas por cobrar

Cuentas por cobrar a relacionadas

Existencias, neto

Total activos corrientes

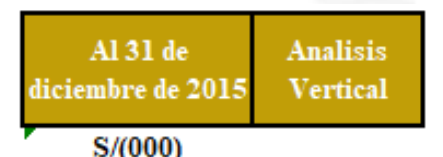

$\mathrm{S} /(000)$

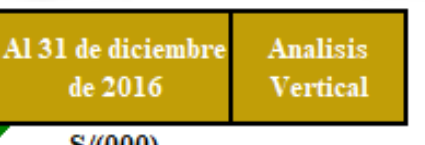

$\mathrm{S} /(000)$
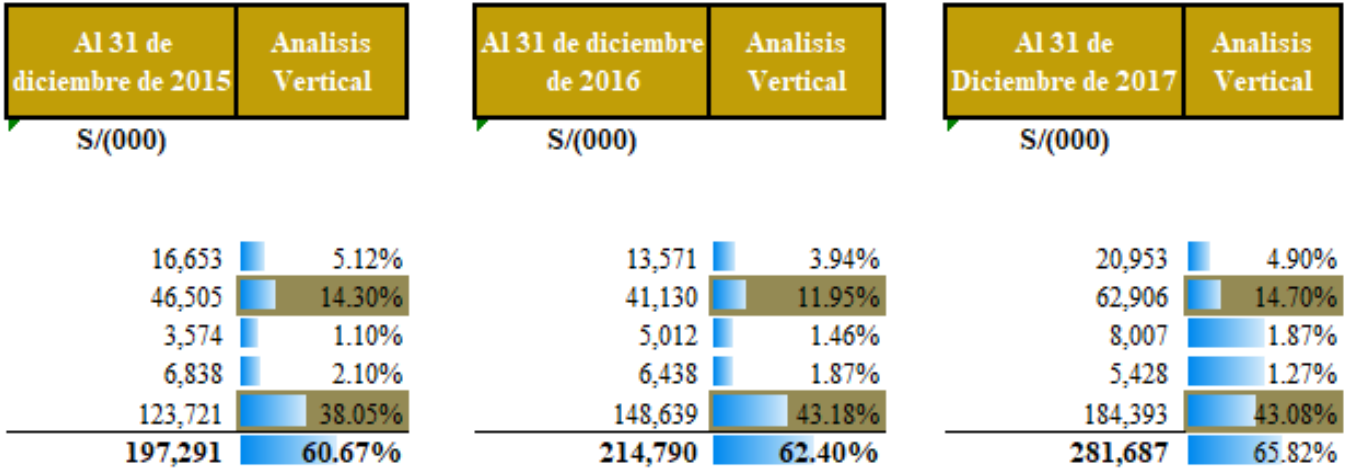

Activos no corrientes

Inventario

Otros activos financieros

Propiedad, planta y equipo, neto

Intangibles

Activo por impuestos a la Ganancia

Diferido

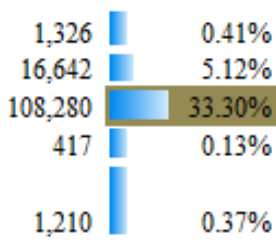

Total activos no corrientes

$\begin{array}{ll}127,874 & 39.33 \%\end{array}$

Total de activos
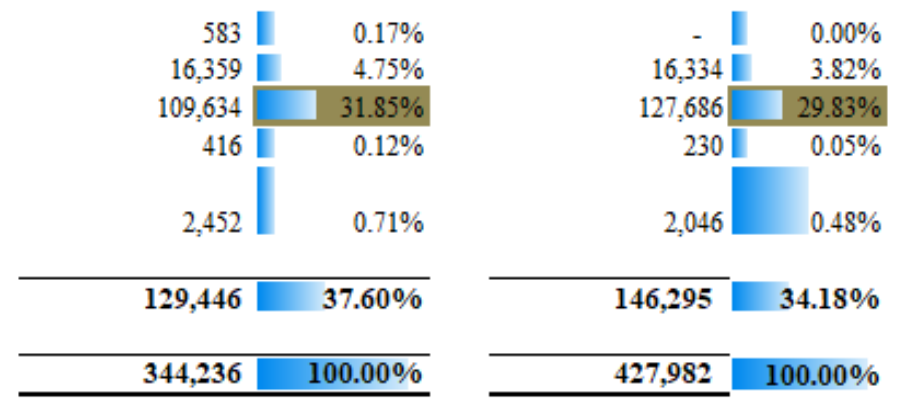

\begin{tabular}{|c|c|c|c|}
\hline & 2018 & 2019 & 2020 \\
\hline \multicolumn{4}{|l|}{ BASE } \\
\hline $4.65 \%$ & $20,631.75$ & 21,374 & $22,143.98$ \\
\hline $13.65 \%$ & 60,520 & 62,699 & 64,956 \\
\hline $1.48 \%$ & 6,541 & 6,777 & 7,021 \\
\hline $1.75 \%$ & 7,747 & 8,026 & 8,315 \\
\hline $41.44 \%$ & 183,729 & 190,344 & 197,196 \\
\hline $62.96 \%$ & 279,169 & 289,219 & 299,631 \\
\hline $0.19 \%$ & 853 & 884 & 916 \\
\hline $4.56 \%$ & 20,229 & 20,957 & 21,711 \\
\hline $31.66 \%$ & 140,381 & 145,435 & 150,671 \\
\hline $0.10 \%$ & 448 & 464 & 480 \\
\hline $0.52 \%$ & 2,309 & 2,392 & 2,479 \\
\hline $37.04 \%$ & 164,220 & 170,132 & 176,256 \\
\hline $100.00 \%$ & 443,389 & 459,351 & 475,888 \\
\hline
\end{tabular}


Pasiros y patrimonio

\section{Pasivo corriente}

Obligaciones Financieras

Cuentas por pagar comerciales

Otras cuentas por pagar

Cuentas por pagar a relacionadas

Total pasivo corriente

Pasiro no corriente

Otros pasivos diferidos

Total pasiros no corrientes

Total de pasiros

Patrimonio

Capital emitido

Acciones de inversión

Excedente de revaluación

Otras reservas de patrimonio

Resultados acumulados

Total Patrimonio

Total pasiros y patrimonio
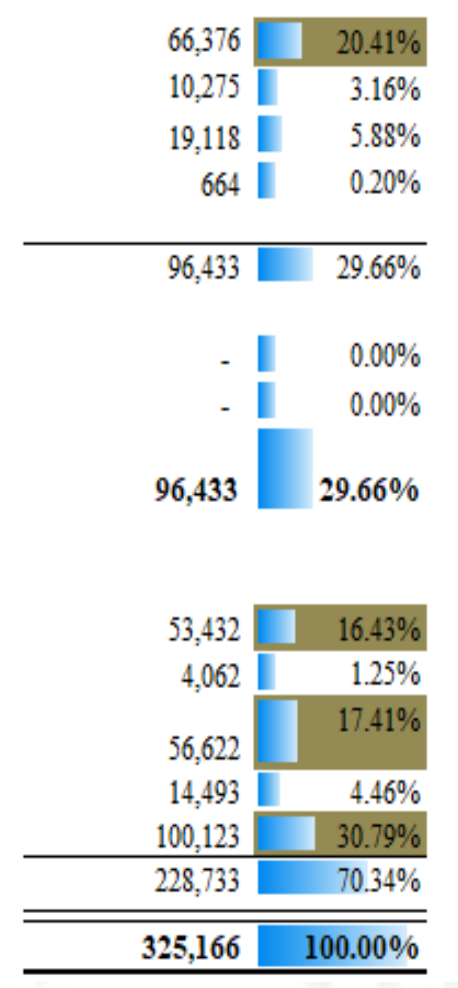
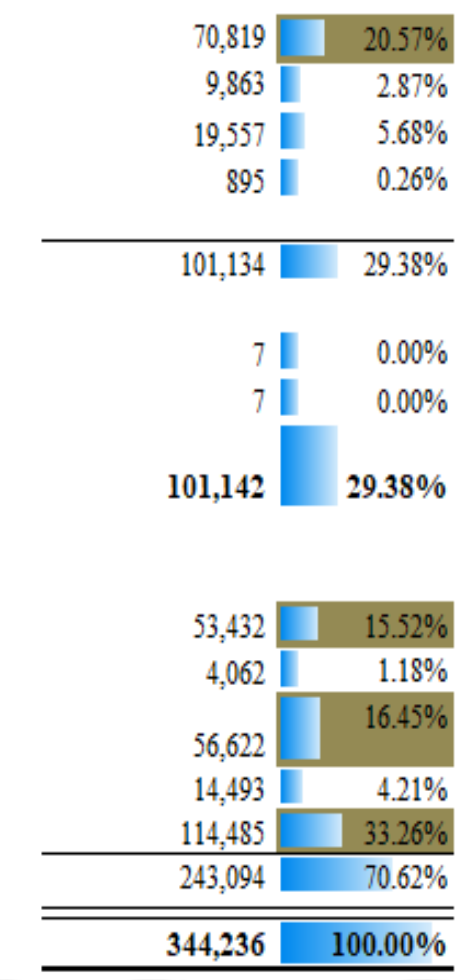
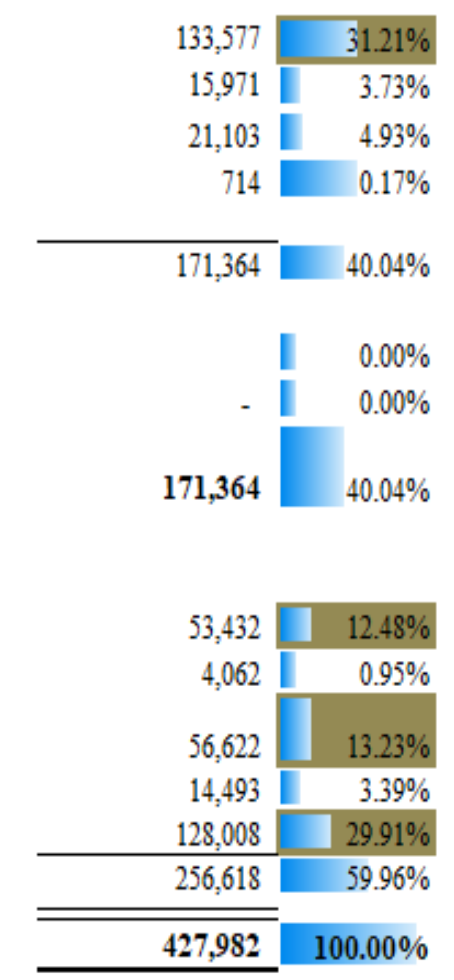

\begin{tabular}{|rrrr}
\hline $24.07 \%$ & 106,704 & 110,545 & 114,525 \\
$3.25 \%$ & 14,420 & 14,939 & 15,477 \\
$5.50 \%$ & 24,374 & 25,251 & 26,161 \\
$0.21 \%$ & 933 & 966 & 1,001 \\
\hline $33.03 \%$ & $\mathbf{1 4 6 , 4 3 1}$ & $\mathbf{1 5 1 , 7 0 2}$ & $\mathbf{1 5 7 , 1 6 3}$ \\
\hline $0.00 \%$ & & 3 & 3 \\
\hline $0.00 \%$ & 3 & 3 & $\mathbf{3}$ \\
\hline $\mathbf{3 3 . 0 3} \%$ & $\mathbf{1 4 6 , 4 3 4}$ & $\mathbf{1 5 1 , 7 0 5}$ & $\mathbf{1 5 7 , 1 6 7}$ \\
\hline & & & \\
\hline $14.81 \%$ & 53,432 & 53,432 & 53,432 \\
\hline $1.13 \%$ & 4,062 & 4,062 & 4,062 \\
\hline $15.70 \%$ & 56,622 & 56,622 & 56,622 \\
\hline 0 & 14,493 & 14,493 & 14,493 \\
\hline $31.32 \%$ & 168,346 & 179,036 & 190,112 \\
\hline $66.97 \%$ & $\mathbf{2 9 6 , 9 5 6}$ & $\mathbf{3 0 7 , 6 4 5}$ & $\mathbf{3 1 8 , 7 2 1}$ \\
\hline $\mathbf{1 0 0 . 0 0 \%}$ & 443,389 & $\mathbf{4 5 9 , 3 5 1}$ & $4 \mathbf{7 5 , 8 8 8}$ \\
\hline & & & \\
\hline
\end{tabular}




\section{Anexo 7: Proyección del Ratios Financieros 2018-2020}

$\underline{\text { Ratios de Liquidez }}$

\begin{tabular}{|l|c|c|c|}
\hline Capital de Trabajo & 132,739 & 137,517 & 142,468 \\
\hline Razón corriente & \multicolumn{3}{|c|}{1.91} \\
\hline Ratio de Prueba acida & \multicolumn{3}{|c|}{0.65} \\
\hline Ratio de Prueba defensiva & \multicolumn{3}{|c|}{0.14} \\
\hline
\end{tabular}

\section{Ratios de Gestión}

\begin{tabular}{|l|c|}
\hline Periodo promedio de cobro & 56.42 \\
\hline Periodo promedio de pago & 17.69 \\
\hline Periodo promedio de inventarios & 225.38 \\
\hline
\end{tabular}

Ciclo Operativo

Ciclo de conversión de efectivo

281.80

264.11 
$\underline{\text { Ratios de Solvencia }}$

\begin{tabular}{|l|c|}
\hline Ratio de deuda & 0.33 \\
\hline Ratio de endeudamiento total & 0.49 \\
\hline Ratio de endeudamiento CP & 0.49 \\
\hline Ratio de cobertura de Gastos Financieros & 21.34 \\
\hline
\end{tabular}

\section{$\underline{\text { Ratios de actividad }}$}

\begin{tabular}{|l|c|}
\hline Ratio de bancos y caja & 19.23 \\
\hline Ratio de rotacion de Activos & 0.88 \\
\hline Ratio de rotacion de Activo Fijo & 2.79 \\
\hline
\end{tabular}

\section{$\underline{\text { Ratios de rentabilidad }}$}

\begin{tabular}{|c|c|c|c|}
\hline Rentabilidad de Capital Propio (ROE) & \multicolumn{3}{|c|}{0.11} \\
\hline Rentabilidad sobre Activos (ROA) & \multicolumn{3}{|c|}{0.07} \\
\hline Margen Bruto & \multicolumn{3}{|c|}{0.24} \\
\hline Margen Neto & \multicolumn{3}{|c|}{0.08} \\
\hline Margen Operativo & \multicolumn{3}{|c|}{0.12} \\
\hline EBITDA & 77,749 & 80,558 & 83,468 \\
\hline
\end{tabular}

